\title{
Apoptotic Sphingolipid Ceramide in Cancer Therapy
}

\author{
Wei-Ching Huang, ${ }^{1,2}$ Chia-Ling Chen, ${ }^{3}$ Yee-Shin Lin, ${ }^{1,3}$ and Chiou-Feng Lin ${ }^{1,2,3}$ \\ ${ }^{1}$ Institute of Basic Medical Sciences, College of Medicine, National Cheng Kung University, Tainan 701, Taiwan \\ ${ }^{2}$ Institute of Clinical Medicine, College of Medicine, National Cheng Kung University, Tainan 701, Taiwan \\ ${ }^{3}$ Department of Microbiology and Immunology, College of Medicine, National Cheng Kung University, Tainan 701, Taiwan
}

Correspondence should be addressed to Chiou-Feng Lin, cflin@mail.ncku.edu.tw

Received 24 August 2010; Accepted 26 October 2010

Academic Editor: Xian-Cheng Jiang

Copyright ( $\odot 2011$ Wei-Ching Huang et al. This is an open access article distributed under the Creative Commons Attribution License, which permits unrestricted use, distribution, and reproduction in any medium, provided the original work is properly cited.

Apoptosis, also called programmed cell death, is physiologically and pathologically involved in cellular homeostasis. Escape of apoptotic signaling is a critical strategy commonly used for cancer tumorigenesis. Ceramide, a derivative of sphingolipid breakdown products, acts as second messenger for multiple extracellular stimuli including growth factors, chemical agents, and environmental stresses, such as hypoxia, and heat stress as well as irradiation. Also, ceramide acts as tumor-suppressor lipid because a variety of stress stimuli cause apoptosis by increasing intracellular ceramide to initiate apoptotic signaling. Defects on ceramide generation and sphingolipid metabolism are developed for cancer cell survival and cancer therapy resistance. Alternatively, targeting ceramide metabolism to correct these defects might provide opportunities to overcome cancer therapy resistance.

\section{Introduction}

Apoptosis, also named programmed cell death, is a normal component for cellular homeostasis involving embryonic/organ development and health in human. For tumorigenesis, oncogenic factors are generally involved in activation of antiapoptotic signaling pathways, whereas tumor suppressor factors are normally proapoptotic [1]. During the past two decades, studies of sphingolipids reveal the important role of bioactive sphingolipids, such as ceramide, in regulation of multiple biological functions especially in apoptosis [2-6]. The cytopathic effects of ceramide are proapoptotic as well as necroticlike, depending on the cell types and the dosages of stimulation. Thus, apoptotic signaling caused by ceramide is diverse because several intracellular organelles are generally involved [7]. Inhibiting cell death by interference on ceramide signaling is a key strategy for tumorigenesis escape from apoptotic stimuli. Therefore, for the development of cancer therapy, ceramide metabolic pathways become candidate target currently [8-11].

The antiproliferative activities of ceramide for cancer therapy depend on the induction of various apoptotic pathways as demonstrated previously [12-14]. Most of these studies are based on the exogenous administration of ceramide analogue, particularly C2- and C6-ceramide. Endogenous generation of ceramide through the newly de novo synthesis or the hydrolysis of sphingomyelin is also reported to trigger signaling pathways after apoptotic stimulation. However, it remains controversial for verifying the different molecular mechanisms between these two experimental approaches. In this article, we briefly discussed the link of ceramide and organelle dysfunction in apoptosis and also summarized several ceramide-based mechanisms of cancer therapy resistance as well as strategies by targeting ceramide metabolism for cancer therapy sensitization.

\section{Apoptotic Signaling through the Multiple Intracellular Organelle Failure}

Under apoptotic stimuli, cells undergo programmed cell death generally through the extrinsic pathway, also called the death receptor pathway, and the intrinsic pathway, also named the mitochondrial pathway [1]. In general, extrinsic pathways are activated by the death receptors through the interaction between their natural ligands or by inducing death receptor clusterization. Death receptors belong to the tumor necrosis factor (TNF) superfamily 
and interact with their ligands to form death receptor complexes, including Fas (CD95/Apo1)/Fas Ligand (CD95 ligand) [15], TNF receptor 1 (p55)/TNF and lymphotoxin [16], TRAMP (WSL-1/Apo3/DR3/LARD)/TWEAK (Apo3 ligand) [17], TRAIL-R1 (DR4)/TRAIL (Apo2 ligand) [18], and TRAIL-R2 (DR5/Apo2/KILLER)/TRAIL [19]. Upon the activation of extrinsic pathway, the intracellular death domain (DD) of death receptors interacts with an adaptor protein Fas-associated death domain (FADD) directly or indirectly via the TNF receptor-associated death domain [19]. The FADD complex interacts with a typical initial procaspase- 8 to form a death-inducing signaling complex required for the activation of caspase- 8 [19]. Caspase- 8 is able to cleave Bid to form a truncated form of Bid (tBid) and causes a reduction of mitochondrial transmembrane potential (MTP) followed by the release of cytochrome $c$, which binds to Apaf- 1 and promotes caspase- 9 and caspase- 3 activation $[20,21]$.

In addition to the extrinsic pathway, the involvement of mitochondrial injury in apoptosis is proposed to be via an intrinsic pathway. Generally, activation of proapoptotic Bax and Bid, the members of the Bcl-2 family with proapoptotic roles, leads to its translocation to the mitochondria and disrupt the membrane integrity to induce MTP [22-24]. In contrast, $\mathrm{Bcl}-2$ and $\mathrm{Bcl}-\mathrm{xL}$, the members of the $\mathrm{Bcl}-$ 2 family with antiapoptotic roles, protect these effects by maintaining the MTP through the inhibition of Bax or other proapoptotic factors [22]. Dysregulation on the balance of $\mathrm{Bcl}-2 / \mathrm{Bax}$ contributes to the progression of apoptosis of intrinsic pathway.

Stresses on the endoplasmic reticulum (ER), which is the site of protein synthesis, modification, and folding, can trigger an unfolded protein response (UPR) following ER stress [25-27]. ER stress can be caused by the inhibition of glycosylation, the reduction of disulfide bonds, calcium depletion from the ER lumen, impairment of protein transport to the Golgi, and expression of mutated proteins in the ER. UPR of ER stress enhances protein folding and degradation within the ER and downregulates protein synthesis until cells have recovered from the ER stress. However, ER stress may also cause apoptotic cell death by the prolonged UPR and is demonstrated to be involved in several apoptotic signaling pathways [25]. The ER stress-induced transcription factor C/EBP homologous protein decreases the expression of antiapoptotic Bcl-2 and increases reactive oxygen species (ROS) production to trigger cell apoptosis through the mitochondrial pathway [26]. Apoptosis signal-regulating kinase (ASK) 1, an upstream kinase of c-Jun N-terminal kinase (JNK), is activated in cells through death receptors and oxidative stress [28]. ER stress can also activate ASK1. Deficiency on ASK1 reduces ER stress-induced JNK activation and cell death [29]. Cascade activation of caspases is generally involved in ER stress-induced cell apoptosis. Caspase-4, a specific ER stress-activated caspase with homology to murine caspase12, triggers apoptotic pathways, dependent or independent of caspase-9 and caspase-3 activation [25]. The crosstalk between ER and mitochondria is therefore speculated. Meanwhile, the activation of caspase- $2,-3,-7,-8$, and -9 has also been reported in ER stress-induced apoptosis [30-32]. A feedback regulation of these caspases has been proposed to be mediated by ER stress-activated calcium-dependent protease calpain. Initially, activated calpain directly causes the activation of human caspase-4 $[33,34]$.

For cell death, acidic organelle lysosome plays a pivotal role in apoptosis and necrosis caused by oxidative stress, TNF- $\alpha$, sphingosine, p53, and staurosporine $[35,36]$. Mechanistic studies show that destabilization of lysosomal membrane and release of lysosomal content into the cytoplasm initiate the lysosomal apoptotic pathway. In general, mitochondrial/lysosomal crosstalk is regularly involved in cell death process. However, the precise lysosomal pathway in ER stress-induced apoptosis remains unclear. Signaling of apoptotic stimuli, such as calcium, ROS, ceramide, sphingosine, phospholipase, Bax, Bim, Bid, and caspase causes lysosomal membrane permeabilization (LMP) [36, 37]. After LMP, cathepsins, the lysosomal proteases, translocate to the cytosol and trigger apoptotic and necrotic pathways through Bid truncation, caspase activation, and mitochondrial damage [38]. Overall, it is speculated that both ER stress and lysosomal and mitochondrial destabilization may contribute to the initiation stage of apoptosis. Inducing mitochondrial pathway is the major proapoptotic actions of ceramide, meanwhile, ceramide also causes lysosomal and ER dysfunction to facilitate apoptotic process. The crosstalk among these organelles in ceramide-induced apoptosis varies in the context of cell types and stimulations.

\section{Sphingolipid Metabolism}

Membrane sphingolipids, regulators for cell growth, death, senescence, adhesion, migration, inflammation, angiogenesis, and intracellular trafficking, are bioactive metabolites including sphingosine, ceramide, sphingosine-1-phosphate (S1P), and ceramide-1-phosphate (C1P) [2]. Ceramide, a sphingolipid with sphingosine backbone, is generated from diverse pathways, including newly de novo synthesis and hydrolysis of sphingomyelin or cerebrosides $[8,13,39,40]$. For de novo synthesis, ceramide is produced by palmitoyltransferase-mediated interaction of serine and palmitoyl-CoA and then a series of metabolic reactions. Alternatively, extracellular stimulation usually induces hydrolysis of sphingolipids and sphingomyelin by sphingomyelinase (SMase) and cerebrosides-including galactosylceramide and glucosylceramide by cerebrosidase.

For the homeostasis of sphingolipid metabolism, ceramide is subsequently metabolized by ceramide kinase to generate $\mathrm{C} 1 \mathrm{P}$ and by ceramidase to generate sphingosine, which is further phosphorylated to S1P by sphingosine kinase. Alternatively again, dephosphorylation of the metabolic derivates also occurs using specific phosphatases, such as C1P phosphatase and S1P phosphatase. Furthermore, ceramide can also be produced from sphingosine by ceramide synthase $[8,13]$. As summarized in Figure 1 , the dynamic regulation for ceramide generation and metabolism is critical for cellular responses to extracellular stimuli, such as death receptor-mediated (TNF- $\alpha$ and Fas), 


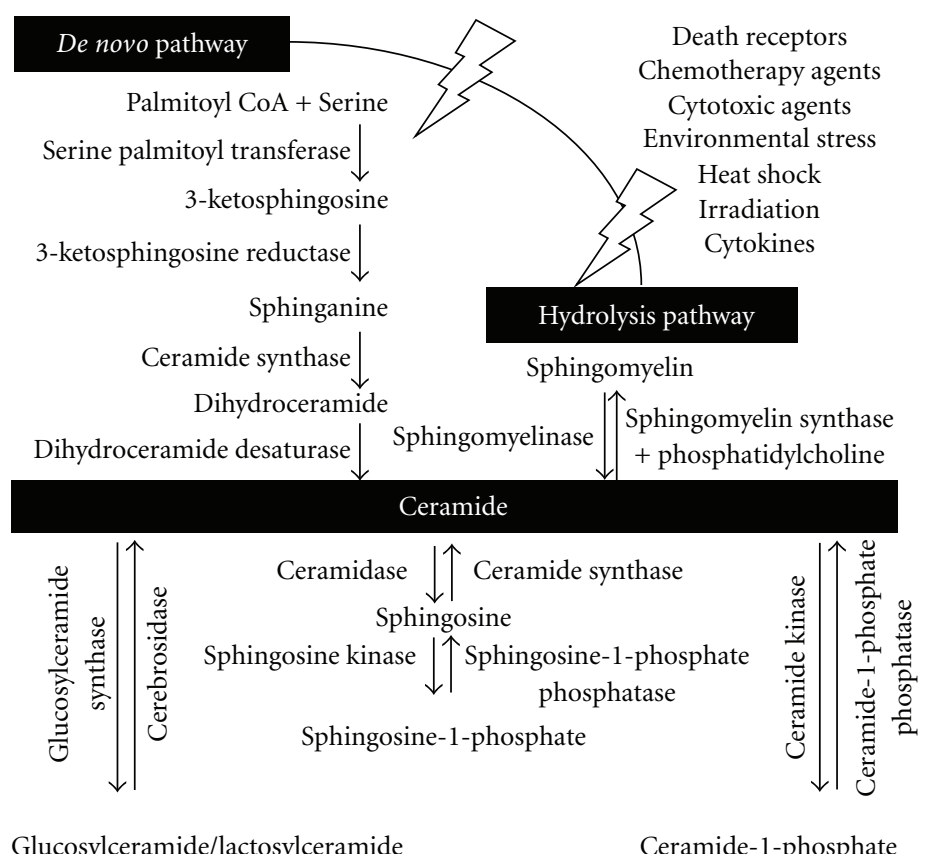

FIgURE 1: Metabolic pathways of ceramide. Under apoptotic stimuli, ceramide is generated primarily by de novo synthesis, through serine palmitoyltransferase- and ceramide synthase-mediated synthesis, and the hydrolysis of sphingomyelin through sphingomyelinase. Furthermore, metabolism of ceramide are regulated by ceramide kinase, sphingosine kinase, ceramide-1-phosphate phosphatase, sphingosine-1-phosphate phosphatase, cerebrosidase, and glucosylceramide synthase.

chemotherapeutic agent-mediated (etoposide, cisplatin, doxorubicin, paclitaxel, and inostamycin), and irradiationmediated (UV and $\gamma$-irradiation) [12-14]. For tumorigenesis, ceramide acts as a tumor-suppressor lipid, whereas S1P acts as a tumor-promoting lipid [8].

A variety of sphingolipid metabolic disorders has been reported because of a deregulated balance on sphingolipid metabolism. Activation of S1P is essential for brain and cardiac development as well as for pathogenic in autoimmunity, cancer, and cardiovascular disease [4]. Ceramide, C1P, and S1P are able to facilitate activation of proinflammatory transcription factors in different cell types to induce overexpression of proinflammatory cyclooxygenase-2 (COX2) and prostaglandins [41]. Additionally, COX2 inhibitor celecoxib has been reported to induce apoptosis via activating ceramide de novo synthesis [42]. Deregulated ceramide facilitates the progressive neurodegenerative diseases such as Alzheimer's disease, Parkinson's disease, amyotrophic lateral sclerosis, and other neurological disorders that are characterized by the gradual loss of specific populations of neurons through the induction of neuronal cell apoptosis $[7,43]$.

\section{Proapoptotic Role of Ceramide}

Several lines of evidence have established the proapoptotic role of ceramide. Many apoptotic stimuli have been found to increase the levels of intracellular ceramide [12-14]. The role of ceramide had been speculated to be proapoptotic based on the observation that ceramide generation precedes the onset of apoptotic signaling [44], and exogenous treatment with ceramide induces cell apoptosis [45]. Figure 2 reveals the generation of ceramide in an apoptotic cell, typically with DNA fragmentation, under hyperglycemia treatment as detected by immunostaining using a monoclonal IgM against cemaride (clone MID 15B4). However, the causal relationships between ceramide generation and apoptosis had been in controversy for a while [46-48]. The advances in ceramide detecting methods and the discoveries of enzyme inhibitors to block ceramide synthesis or increase ceramide accumulation further identified that some ceramidegenerating stimuli induce apoptosis in ceramide-dependent manner [12].

Ceramide is important mediator in both extrinsic and intrinsic pathways of apoptosis [6, 7, 12]. Endogenous ceramide generation and its roles in apoptotic signaling have been demonstrated in CD95- and TNF- $\alpha$-treated conditions [49]. In these cells, acidic SMase mediates hydrolysis of sphingomyelin to generate ceramide and inhibition of acidic SMase effectively blocks cell death [50-52]. In addition to acidic SMase, TNF- $\alpha$ activates neutral SMase through FAN (factor associated with neutral SMase activation) to induced apoptosis [53]. Intrinsic apoptotic stimuli such as hypoxia, nutrient deprivation, radiation, heat, cellular stress, and cytotoxic drugs also increase endogenous ceramide levels through multiple mechanisms involving not only SMase but also ceramide synthase [2]. In general, increased ceramide causes activation of various protein kinases and phosphatases, cascade activation of caspases, dysfunction of multiple organelles, and leads to apoptosis [7]. 


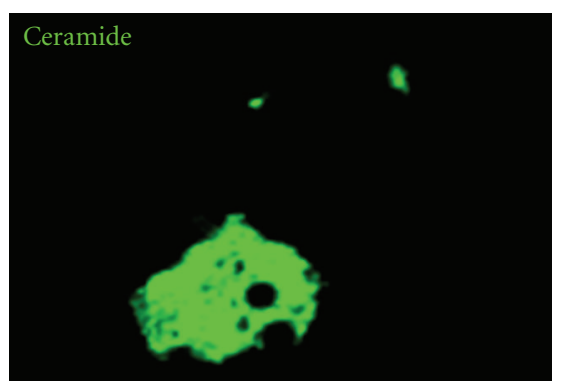

(a)

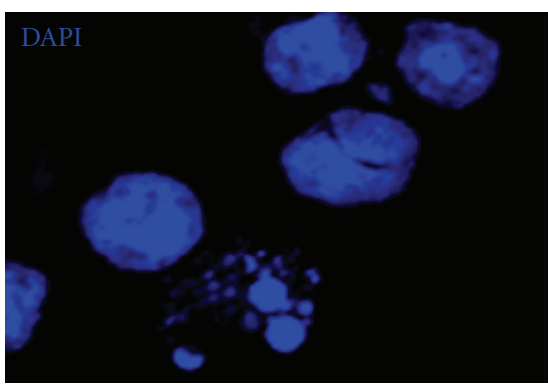

(b)

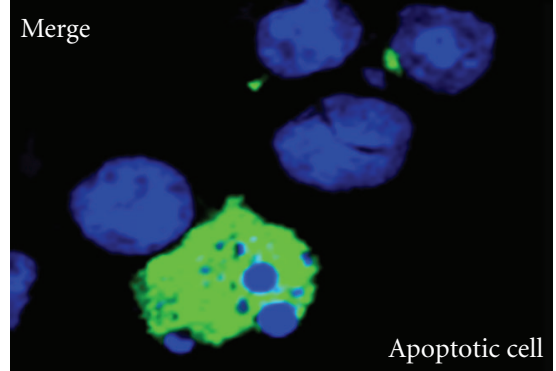

(c)

Figure 2: The generation of ceramide in apoptotic cells. Under high dose $(25 \mathrm{mM})$ treatment of glucose (mimic hyperglycemia), mouse $\mathrm{T}$ hybridoma 10I cells underwent apoptosis were detected by 4',6-diamidino-2-phenylindole (DAPI) nuclear staing. Fluorescein isothiocyanate-conjugated ceramide monoclonal IgM was used to detect ceramide generated in response to hyperglycemia.

Ceramide is structurally composed of a fatty acyl moiety bound to an amino alcoholic chain which varies in length from $2 \sim 28$ carbons. Long-chain ceramide belongs to the natural form of ceramide found in cells. Short chain ceramides are usually synthesized for the purpose of research [54]. Obeid et al. [45] firstly identified the proapoptotic role of ceramide in vitro by using C2-ceramide (microM), a synthetic cell-permeable ceramide analog $\mathrm{N}$-acetylsphingosine. Typically, C2-ceramide, but not dihydroceramide, induces internucleosomal DNA fragmentation, a characteristic for cell apoptosis [55]. In addition to C2-ceramide, C6-ceramide also triggers cell undergoing apoptosis [56]. After that, ceramide acts as a lipid second messenger as reported in a number of researches of apoptotic signaling pathways $[57,58]$. In cancer cells, taking leukemia for instance, exogenous treatment of $\mathrm{C} 2$ - and C6-ceramide induced apoptosis in chronic myeloid leukemia (CML) cell line K562 $[59,60]$. C6-ceramide promotes apoptosis in CMLderived K562 cells by a mechanism involving caspase- 8 and JNK [59]. Nanoliposomal delivery of exogenous ceramide (C6-ceramide) inhibit NK-LGL leukemia in a rat model and the antiproliferative effect of ceramide is through downregulation of antiapoptotic protein survivin [61].

Whether exogenous ceramide mimic intracellular physical actions of endogenous ceramide remains an open question. However, it is of note that treatment of cells with exogenous ceramide (at concentration below 20 microM

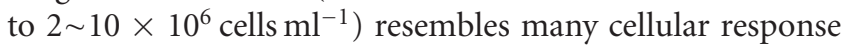
induced by ceramide-generating stimuli [13]. Exogenous ceramide has been reported to induce endogenous ceramide through ceramide synthase [62]. Meanwhile, several interesting findings provide insight that the biologic functions of ceramide may vary by its length. Differential expression of C16- (high) and C18-ceramide (low) in patients with head and neck squamous cell carcinomas (HNSCCs) suggests the C18-ceramide play proapoptotic role but not C16-ceramide [63-65]. Knockdown of C16-ceramide synthase (ceramide synthase 6; CerS6) induces ER stress and apoptosis in vitro [66]. The growth of HNSCCs xenograft is promoted by overexpression of CerS6 but suppressed by overexpression of CerS1 (C18-ceramide synthase) [66]. The individual function of ceramide species needs more investigations.
Early evidence that $\mathrm{Bcl}-2$ prevents ceramide-induced apoptosis [56, 67] demonstrates exogenous ceramide initiates mitochondrial apoptosis. In cell-free system, C2ceramide induces ROS generation and inhibits mitochondrial electron transfer in isolated mitochondria [68-70]. C2- or C16-ceramide causes increase of mitochondrial outer membrane permeability which allows cytochrome $c$ release $[71,72]$. Ceramide can be generated in mitochondria through hydrolysis or de novo synthesis [73-75]. Both mitochondrial-overexpressed sphingomyelinase and TNF- $\alpha$ stimulation leads to mitochondrial ceramide accumulation, Bax translocation, cytochrome $c$ release, and apoptosis $[73,76]$. Exogenous C2- or C6-ceramide also triggers mitochondrial apoptosis in multiple cell lines [77-80]. In general, either exogenous ceramides or ceramide-generating death stimuli cause mitochondrial dysfunction, executor caspases activation, and apoptosis.

Compared with the field of mitochondrial apoptosis, much less studies address the role of ER in ceramideinduced apoptotic signaling. In addition to protein synthesis, ceramide is also de novo synthesized in the ER and transfer to Golgi apparatus by ceramide transport protein CERT $[2,3,81]$. The hypothesis that perturbation of ceramide level in ER might cause ER stress is deducible but needs more evidence. Knockdown of C16-ceramide synthase (CerS6) or C24-ceramide synthase (CerS2) induces ER stress $[66,82]$. In glioma cells, tetrahydrocannabinol (THC) induces apoptosis through de novo synthesized ceramide-mediated $\mathrm{p} 8$ upregulation, which further trigger ER stress (induction of ATF4 and CHOP) [83]. Combination of histone deacetylase inhibitor vorinostat and multikinase inhibitor sorafenib induces de novo synthesized and acidic SMase hydrolyzed ceramide to upregulate CD95 to trigger ER stress (activation of PERK) [84]. CERT is identified to influence sensitivity of different cancer cell types to chemotherapeutic agents in a siRNA-based screening [85]. Downregulation of CERT sensitizes cancer cells to chemotherapeutic drugs and induces ER stress [85, 86]. Our previous report showed C2-ceramide and etoposide induce ER stress-related proteins Bip, CHOP, caspase-4, and PERK activation [87]. Requirement of ASK1 and JNK signaling is reported in both ceramide- and ER stress-induced apoptosis $[28,29,87,88]$. Taken together, 


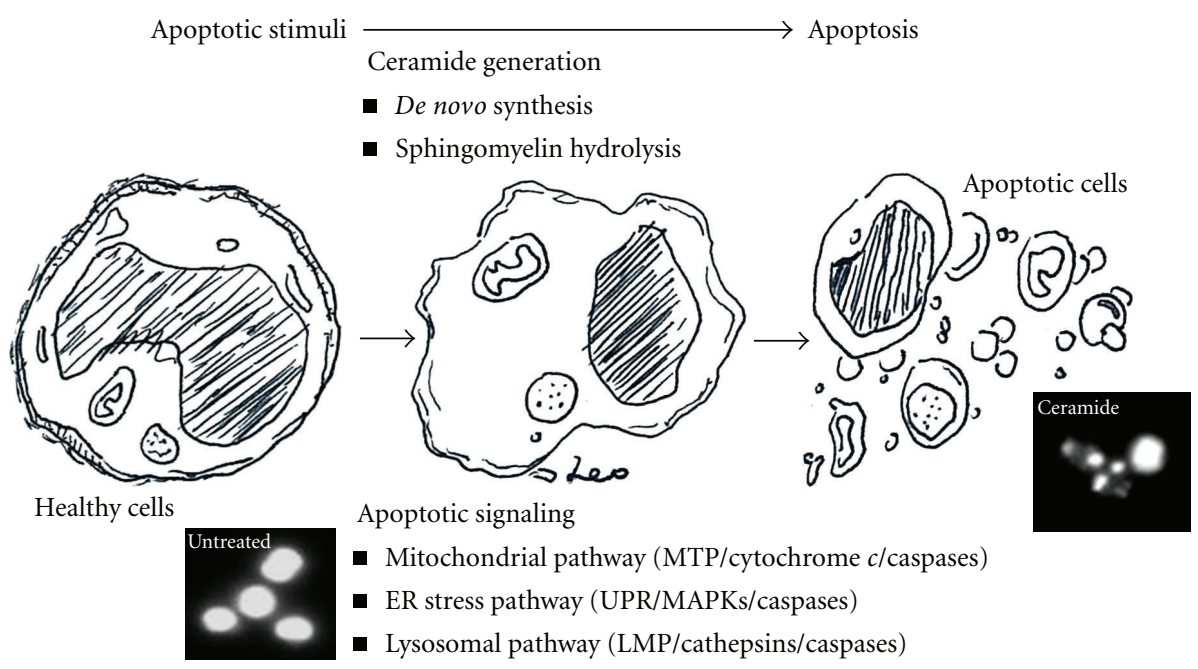

FIgUre 3: Proapoptotic ceramide. Apoptotic stimuli cause ceramide generation. Proapoptotic ceramide triggers apoptotic signaling through multiple mechanisms involving mitochondrial-, ER stress-, and lysosomal-regulated pathways.

these findings suggest that ceramide induces ER stress; however, more investigations are needed to dissect the causal relationships and regulatory mechanisms between ER stress and ceramide-induced apoptosis. In addition, free fatty acid (FFA) has been reported to induce pathological ER stress and lead to metabolic disorders such as insulin resistance, obesity, steatosis, diabetes, and atherosclerosis [89-91]. The role of ceramide in insulin resistance has also been reported $[92,93]$. Studies showed FFA activates ceramide de novo synthesis in islet $\beta$ cells to induce apoptosis [94] and in astrocytes to increase $A \beta$ protein expression and tau protein hyperphosphorylation [95]. However, another report demonstrated a ceramide-independent way of FFA to induce ER stress in liver cells [96]. More evidence is needed to better understand the regulation of ceramide in FFA-induced ER stress and downstream biological effects.

The mechanism by which ceramide triggers lysosomal apoptosis involves acid sphingomyelinase and cathepsin D [97-99]. Ceramide generated by acid SMase can directly interact with cathepsin D and mediate its activation [99101]. In response to TNF- $\alpha$ stimulation, lysosomal acid SMase mediates ceramide generation to activate cathepsin $\mathrm{D}$ and downstream apoptotic signaling such Bid truncation and mitochondrial dysfunction [97]. Similar pathway has been recently reported in treatment of glioma cells with chemotherapeutic drug gemcitabine [99]. Exogenous treatment with C2-ceramide triggers this pathway in 10I hybridoma and A549 lung adenocarcinoma cells, however; different mechanism might exist because inhibiting acid SMase did not reduce LMP and apoptosis (Huang et al., unpublished data). Moreover, one study reported FFAinduced LMP and apoptosis in liver cells independently of ceramide de novo synthesis [102]. Concerning the findings of FFA-induced ER stress, the signaling pathways of FFA-induced apoptosis might have ceramide-dependent and -independent routes in triggering ER and lysosome dysfunction.
In summary as shown in Figure 3, ceramide mediates dysfunction of multiple intracellular organelles followed by apoptosis. More investigations are needed to fully understand the cell type- and stimulus-dependent mechanisms of how ceramide causes organelles dysfunction and the crosstalk among these organelles.

\section{Regulation of Apoptotic Ceramide in Cancer Therapy Resistance}

Cancer cells resist therapy in multiple mechanisms including escape from therapy-induced apoptosis [122-124]. Since the proapoptotic role of ceramide in cellular regulation is well established, either endogenous or exogenous ceramide contributes to the suppression of cancer progression $[8,14,58]$. On the other hand, cancer cells also gain survival advantages against therapy by impairing sphingolipids metabolism to reduce proapoptotic ceramide generation and accumulation $[8,9,11,125]$. More than 30 enzymes are identified to regulate intracellular ceramide. Among them, glucosylceramide synthase, ceramidase, and sphingosine kinase are recently found to be targets for cancer cells to avoid killing of treatment. Here we summarized the findings about their roles in regulation of cancer therapy resistance (also listed in Table 1).

5.1. Glucosylceramide Synthase (GCS). Relationships between GCS and chemoresistance have been reported in various kinds of cancer cells and addressed in breast cancer most completely. In studies to compare the lipid compounds of drug-sensitive and -resistant cancer cell lines, glucosylceramides accumulation are found in drugsensitive cells [126-129]. Ectopic expression of GCS increases chemoresistance of drug-sensitive cells. Reciprocally, genetic silencing and pharmacological inhibition of GCS sensitizes drug-resistant cells to multiple chemotherapeutic drugs, such as adriamycin, Vinca alkaloids, doxorubicin, etoposide, 
TABLE 1: Targeting ceramide metabolic enzymes alters drug resistance in cancers.

\begin{tabular}{|c|c|c|c|c|}
\hline Enzymes & Cancer species (cell line) & Drug & Resistance & Reference \\
\hline \multirow{7}{*}{ GCS $\uparrow$} & Breast cancer (MCF-7) & Adriamycin & $\uparrow$ & {$[103,104]$} \\
\hline & Colon cancer (SW620) & Adriamycin & $\uparrow$ & {$[104]$} \\
\hline & \multirow{2}{*}{ Epidermoid carcinoma (KB-3-1) } & Adriamycin & \multirow[t]{2}{*}{$\uparrow$} & \multirow[t]{2}{*}[104]{} \\
\hline & & Vinblastine & & \\
\hline & Leukemia (HL-60) & Vincristine & $\uparrow$ & {$[104]$} \\
\hline & Melanoma (MeWo) & Etoposide & $\uparrow$ & {$[104]$} \\
\hline & Leukemia (HL-60) & Doxorubicin & $\uparrow$ & {$[105]$} \\
\hline \multirow{8}{*}{ GCS $\downarrow$} & Adriamycin-resistant MCF-7 & Adriamycin & $\downarrow$ & {$[106]$} \\
\hline & Adriamycin-resistant MCF-7 & $\begin{array}{l}\text { Vinblastine } \\
\text { Paclitaxel }\end{array}$ & $\downarrow$ & {$[107]$} \\
\hline & $\begin{array}{l}\text { Adriamycin-resistant MCF-7 and murine } \\
\text { breast cancer (EMT6) }\end{array}$ & Doxorubicin & $\downarrow$ & {$[108,109]$} \\
\hline & Adriamycin-resistant SW620 & Doxorubicin & $\downarrow$ & {$[108]$} \\
\hline & $\begin{array}{l}\text { Doxorubicin-resistant ovarian carcinoma } \\
\text { (A2780) }\end{array}$ & Doxorubicin & $\downarrow$ & {$[108]$} \\
\hline & Doxorubicin-resistant cervical cancer (KB-A1) & Doxorubicin & $\downarrow$ & {$[108]$} \\
\hline & Hepatoma (HepG2) & Doxorubicin & $\downarrow$ & {$[110]$} \\
\hline & Multidrug-resistant leukemia (K562/A02) & Adriamycin & $\downarrow$ & {$[111]$} \\
\hline \multirow{4}{*}{ Acid Ceramidase $\uparrow$} & \multirow{4}{*}{ Prostate cancer (DU145) } & Doxorubicin & \multirow{4}{*}{$\uparrow$} & \multirow{4}{*}[112]{} \\
\hline & & Cisplatin & & \\
\hline & & Etoposide & & \\
\hline & & Gemcitabine & & \\
\hline Acid Ceramidase $\downarrow$ & $\begin{array}{l}\text { Hepatoma (HepG2, Hep-3B, SK-Hep and } \\
\text { Hepa1c1c7) }\end{array}$ & Daunorubicin & $\downarrow$ & {$[113]$} \\
\hline \multirow{3}{*}{ SphK1 $\uparrow$} & Ovarian cancer $(\mathrm{A} 2780)$ & 4-HPR & $\uparrow$ & {$[114]$} \\
\hline & Leukemia (HL-60) & $\begin{array}{l}\text { Doxorubicin } \\
\text { Etoposide }\end{array}$ & $\uparrow$ & {$[115]$} \\
\hline & Pancreatic cancer (Panc-1) & Gemcitabine & $\uparrow$ & {$[116]$} \\
\hline \multirow{4}{*}{ SphK1 $\downarrow$} & 4-HPR-resistant A2780 & 4-HPR & $\downarrow$ & {$[114]$} \\
\hline & Daunorubicin-resistant leukemia (K562) & Daunorubicin & $\downarrow$ & {$[117]$} \\
\hline & Camptothecin-resistant prostate cancer (PC3) & Camptothecin & $\downarrow$ & {$[118]$} \\
\hline & Oxaliplatin-resistant colon cancer (RKO) & Oxaliplatin & $\downarrow$ & {$[119]$} \\
\hline \multirow{2}{*}{ Acid SMase $\uparrow$} & \multirow{2}{*}{ Glioma } & Gemcitabine & \multirow{2}{*}{$\downarrow$} & \multirow{2}{*}[120]{} \\
\hline & & Doxorubicin & & \\
\hline \multirow{3}{*}{ S1P lyase $\uparrow$} & \multirow{3}{*}{ Lung cancer (A549) } & Cisplatin & & \multirow{3}{*}[121]{} \\
\hline & & Carboplatin & $\downarrow$ & \\
\hline & & Doxorubicin & & \\
\hline
\end{tabular}

and paclitaxel $[103,104,107,130]$. A recent in vivo study reported a mixed-backbone oligonucleotide against GCS sensitizes xenograft of multidrug-resistant breast cancer cell to doxorubicin [108]. GCS links multidrug resistance by multiple mechanisms, including reduced concentration of C18-ceramide, increased glycosphingolipids accumulation, and $M D R$ gene upregulation through $c S r c$ and $\beta$-catenin $[104,107-109,130]$. Upregulated MDR gene in turn encodes
P-glycoprotein (P-gp), a drug efflux pump which induces multidrug resistance (MDR) in cancers [131-133]. One study reported that GCS-deficient and -ectopic expressed murine melanoma cells show no difference in the sensitivity to doxorubicin, vinblastine, paclitaxel, cytosine arabinoside, or short-chain ceramide analogs [134]. Another study showed that combining GCS inhibitor enhances doxorubicin-induced ceramide accumulation and apoptosis 
in hepatoma cells by a P-gp-independent manner [110]. These findings suggested that regulation of GCS in chemoresistance depends on cell type and might act through different mechanism.

Besides in breast cancer cells, overexpression of GCS is also found in multidrug-resistant leukemia, melanoma, colon cancer, and head and neck epidermoid carcinoma [104]. For example, in acute myeloid leukemia (AML), the ceramide levels are lower and the activities of GCS and sphingomyelin synthase are higher than in chemosensitive patients. The role of GCS is further confirmed in cell model when overexpression of GCS raised the resistance of HL60 to doxorubicin-induced apoptosis [105]. In CML, drugresistant K562 cells also express higher level of GCS. Pharmacological inhibition using PDMP or genetic silencing of GCS sensitizes drug-resistant K562 cells to adriamycin [111].

GCS and glycosphingolipids are also speculated to involve immune escape and metastasis in cancer $[135,136]$. Overexpression of GCS and high secretion of glycosphingolipids might prevent cancer cell from immune attack by $\mathrm{T}$ cells and antibodies [135]. Preincubation with GCS inhibitor PDMP reduced the metastatic ability of Lewis lung carcinoma 3LL cells injected in mice [136]. However, more investigations are needed.

5.2. Ceramidase. According to the maximal enzymatic activity in acidic, neutral, and alkaline environment, ceramidases are divided into acid, neutral, and alkaline ceramidases. Due to its ability to breakdown ceramide to regulate sphingosine and S1P levels, ceramidases become important regulators in cell survival [137]. Acid ceramidase is overexpressed in prostate cancer [138]. Ectopic expression of acid ceramidase in prostate cancer cell line DU145 shows elevated resistance to doxorubicin-, cisplatin-, etoposide-, gemcitabine- or C6ceramide-induced apoptosis, while silence of acid ceramidase lowers the resistance to those drugs [112]. Acid ceramidase inhibitor B13 induces apoptosis in prostate cancer cell line and xenograft $[139,140]$. In colon carcinomas, ceramide levels are lower than healthy tissue [141] and treatment with exogenous ceramide or ceramidase inhibitor B13 induces apoptosis [141, 142]. Acid ceramidase overexpression prevents fibrosarcoma cell line L929 from TNF- $\alpha$ induced apoptosis and treatment of exogenous ceramide or acid ceramidase inhibitor $N$-oleoylethanolamine overcomes this TNF- $\alpha$ resistance [143]. Overexpression of neutral ceramidase prevents primary hepatocytes from TNF- $\alpha$ induced apoptosis in vitro and inhibits D-galactosamine plus TNF- $\alpha$-induced liver injury in vivo [144]. Another report showed high ectopic expression of alkaline ceramidase 2 in cervical cancer cell line HeLa leads to growth arrest due to sphingosine accumulation and low ectopic expression of alkaline ceramidase promote cell proliferation due to S1P production [145]. A recent study demonstrated silence of alkaline ceramidase 3 inhibits not only cell proliferation but also serum deprivation-induced apoptosis [146]. More evidence is needed to fully understand the regulation of neutral and alkaline ceramidases on the development of therapy resistance in cancer cells.
5.3. Sphingosine Kinase (SphK). Activation of SphK results in the generation of S1P to facilitate survival and therapy resistance in cancer cells. Ample evidence reveals the oncogenic role of SphK1; however, the isoform SphK2 seems to possess not only overlapping role with SphK1 in promoting tumor development but also opposite role in inducing apoptosis $[147,148]$. Therefore, a recent study has developed a new SphK2 specific inhibitor [149] which might be used to further dissect the biological functions between the two isoforms. Overexpression of SphK1 promotes the development erythroleukemia [150]. In CML, which is caused by potent oncogenic protein Bcr-Abl, the activity of sphingosine kinase-1 (SphK1) is elevated by Bcr-Abl to increase expression of antiapoptotic protein Mcl-1 [151] and Bcr-Abl inhibitor imatinib-induced apoptosis through inhibiting SphK1 [152]. In myelodysplastic syndromes and acute leukemia, increased gene expression of SphK1 leads to doxorubicin resistance which in reverse can be abrogated by SphK1 siRNA [117, 153]. In solid tumors, SphK1 is required in the oncogenic signaling of vesicular endothelial growth factor (VEGF), epidermal growth factor (EGF), and Ras [154-156]. Overexpression of SphK1 has been identified in mRNA screening or immunohistochemistry staining in multiple cancer cells derived from breast, colon, lung, ovary, stomach, uterus, kidney, and rectum [157-159]. In human ovarian cancer cells, resistance to chemotherapeutic drug $\mathrm{N}$-(4-hydroxyphenyl)retinamide (4-HPR) is mediated by SphK1 [114]. Prostate cancer cell line PC3 resistant to chemotherapeutic drug camptothecin is found to highly express SphK1 [118]. Higher activity of SphK1 and SphK2 in oxaliplatin-resistant colon cancer cell line RKO and knockdown of either SphK1 or SphK2 abrogates RKO cells oxaliplatin resistance [119]. One report showed hypoxia upregulates SphK2 protein expression as well as enzymatic activity to resist chemotherapeutic drugs-induced cell death in lung cancer cell line A549 [160].

5.4. Acid SMase, S1P Lyase, and CERT. Acid SMase-difficient MS1418 lymphoblasts from patients with Niemann-Pick disease show resistance to UVA and irradiation [161, 162]. An in vivo study also demonstrates mouse deficient in acid SMase showed resistance to irradiation-induced apoptosis [162]. Reciprocally, overexpression of acid SMase sensitizes glioma cells to gemcitabine and doxorubicin [120]. In cancer cells, many apoptotic stresses such as UV, irradiation, doxorubicin, cisplatin, TRAIL, and CD95 activates acid SMase to induce apoptosis $[163,164]$. Activated acid SMase translocates to plasma membrane and increases ceramide to form ceramide-rich platforms (CRPs) which are required in signal transduction and apoptosis $[165,166]$. One report suggested that the low fluidity of plasma membrane may be associated with cisplatin resistance [167]. However, whether cancer cells downregulate acid SMase to reduce CRPs formation and plasma membrane fluidity to achieve drug resistance remains unclear.

Opposite to the proapoptotic role of ceramide, S1P inhibits apoptosis by preventing release of mitochondrial cytotoxic effectors cytochrome $c$ and Smac/DIABLO in several acute human leukemia cell lines [168]. Increasing 
S1P by downregulation of S1P lyase was found to alter $\mathrm{S} 1 \mathrm{P} /$ ceramide rheostat to favor cell survival in colon cancer and ectopic expression of S1P lyase induces apoptosis via p53 and p38 MAPK [169]. Experimentally, using human embryonic kidney cells HEK293, ectopic expression of S1P lyase decreases cell viability and enhances ceramide generation and stress-induced apoptosis, meanwhile, addition of S1P reverses stress-induced apoptosis [170]. Overexpression of S1P lyase in HEK293 and A549 cells showed higher sensitivity to several chemotherapeutic drugs including cisplatin, carboplatin, and doxorubicin [121]. In addition, increased expression of ceramide transport protein CERT is found in residual tumor following paclitaxel treatment of ovarian cancer [85]. Loss of function of CERT leads to ceramide accumulation in ER and sensitizes cancer cells to chemotherapy and radiotherapy $[85,171]$.

\section{Targeting Ceramide Metabolic Pathways to Overcome Cancer Therapy Resistance}

Based on the knowledge that cancer cells develop resistance to therapy by arming themselves with the abilities to avoid generation/accumulation of intracellular proapoptotic ceramide, targeting ceramide metabolic pathways might be potential strategy to improve the response to cancer therapy. This strategy might itself be an alternative therapeutic option or in combination with present cancer therapies to enhance therapeutic efficacy and sensitivity.

Many chemotherapeutic drugs, such as daunorubicin, etoposide, camptothecin, fludarabine, and gemcitabine, have been known to induce ceramide de novo synthesis to mediate cytotoxic effects. Accordingly, it is conceivable that alteration of ceramide metabolism can significantly affect sensitivity of chemotherapy. GCS inhibition can restore sensitivity of drug-resistant cancer cells to multiple chemotherapeutic drugs [104, 106, 107]. The major cause of chemoresistance is therapeutic stress-induced P-gp overexpression which results in MDR. A set of MDR modulators, which bind and interfere with drug efflux, are used in combination of chemotherapeutic drugs to enhance efficacy [172]. MDR modulators sensitize drug-resistant cancer cells to chemotherapy through elevating ceramide levels by activating ceramide synthase or inhibiting GCS [173-176]. Combination of MDR modulators and GCS inhibitor synergistically induce cytotoxicity in various human solid tumor cell lines, including neuroblastoma and melanoma, prostate, lung, colon, breast, and pancreatic cancers [177]. SphK1 inhibitor by itself overcomes MDR-associated chemoresistance in AML and CML cell lines and patient samples and gemcitabine-resistant pancreatic cancer cells $[115,116,178]$. Downregulation of SphK1 or SphK2 enhances sensitivity to doxorubicin in breast cancer cell MCF-7 [179, 180]. One of the sphingolipid breakdown products, sphingosine, by itself induces apoptosis in adriamycin-resistant epidermoid carcinoma cells [181]. Inhibiting acid ceramidase with siRNA or $N$ oleoylethanolamine sensitizes hepatoma cells to daunorubicin [113]. Overexpression of alkaline ceramidase 2 but not alkaline ceramidase 1 or 3 enhances the cytotoxicity of
4-HPR in HeLa cells [182]. A recent report demonstrated combining exogenous C6-ceramide sensitizes multiple cancer cell lines to doxorubicin or etoposide [183].

For overcoming resistance to cancer radiotherapy, we summarize following examples. Defective ceramide metabolism causes resistance to radiation in AML and Burkitt's lymphoma cells $[184,185]$. The defect-inducing proteins are needed to be identified for therapeutic target to improve radiosensitivity. Intracellular ceramide is also precursor of downstream prosurvival glycosphingolipids (precursor of gangliosides). Radioresistant sublines derived from human melanoma cell line M4Be are found rich in gangliosides. Combining fumonisin B1 (inhibitor of ceramide synthase) restore the sensitivity of radioresistant M4Be to radiation [186]. In glioma cells, combining either acid ceramidase inhibitor $N$-oleoylethanolamine or GCS inhibitor PDMP accelerates radiation-induced apoptosis [187, 188].

For overcoming resistance to cancer target therapy and gene therapy, we take CML and HNSCCs for examples. The $\mathrm{Bcr}-\mathrm{Abl}$ tyrosine kinase inhibitor imatinib is the standard target therapy of CML [189]. Imatinib induces apoptosis in $\mathrm{K} 562$ cells via the generation of $\mathrm{C} 18$-ceramide, but this is not observed in imatinib-resistant cells [190]. Overexpression of CerS1 or silence of sphk1 enhances imatinib-induced apoptosis in imatinib-resistant cells [190]. Moreover, in our unpublished data, Bcr-Abl mutation-based imatinib resistance was abrogated by combining ceramide accumulating agents such as GCS inhibitor or ceramidase inhibitor, though in a not well-defined mechanism. Besides combinational treatment, C6-ceramide and SphK1 inhibitor independently induce apoptosis in imatinib-resistant CML cell lines KBM5 and LAMA84s, respectively [59, 152]. Sorafenib (BAY 439006) is a nonspecific inhibitor of RAF/MEK/ERK pathway and receptor tyrosine kinase [191]. Combining sorafenib with either SphK2 or SphK1/2 inhibitor provides enhanced growth inhibition of human pancreatic adenocarcinoma and kidney carcinoma cells in vitro and in vivo [192]. As prostate cancer, HNSCCs are also showed overexpression of acid ceramidase, therefore, acid ceramidase inhibitor is used to increase the cytotoxicity of adenovirus-delivered FasL in HNSCCs [193].

In addition to overcome cancer therapy resistance, targeting ceramide pathway might be a strategy to advance current conventional therapies into novel regimen on different cancer types. For example, sorafenib is approved for clinical use only in renal cell carcinoma [194]. Combining sorafenib with nanoliposomal ceramide enhances sensitivity to sorafenib in another cancer cell types including melanoma and breast cancer [195].

\section{Conclusion}

Cancer therapy resistance is a major problem leading to treatment failure. Mounting evidence indicated the apoptotic sphingolipid — ceramide - as important suppressor in cancer development. Alterations of ceramide metabolism become strategy for cancer cells to develop resistance against therapy. Conversely, manipulation of ceramide metabolism also provides potential alternative and combinational therapeutic 
options. Though, it is challenging to optimize solutions for overcoming resistance due to the complexity of sphingolipids metabolic network. By accumulating knowledge about how cancer cells escape from apoptotic stimuli and the discovery of potent and safe inhibitors, targeting ceramide metabolic pathways still provides opportunities for more feasible and more efficacious cancer therapy.

\section{Acknowledgments}

This work was supported by Grants NSC 96-2320-B-006018-MY3 from the National Science Council, Taiwan, NHRIEX99-9917 from the National Health Research Institutes, Taiwan, and the Landmark project C020 of National Cheng Kung University, Taiwan.

\section{References}

[1] Z. Jin and W. S. El-Deiry, "Overview of cell death signaling pathways," Cancer Biology and Therapy, vol. 4, no. 2, pp. 139163, 2005.

[2] Y. A. Hannun and L. M. Obeid, "Principles of bioactive lipid signalling: lessons from sphingolipids," Nature Reviews Molecular Cell Biology, vol. 9, no. 2, pp. 139-150, 2008.

[3] S. Lahiri and A. H. Futerman, "The metabolism and function of sphingolipids and glycosphingolipids," Cellular and Molecular Life Sciences, vol. 64, no. 17, pp. 2270-2284, 2007.

[4] H. Fyrst and J. D. Saba, "An update on sphingosine-1phosphate and other sphingolipid mediators," Nature Chemical Biology, vol. 6, no. 7, pp. 489-497, 2010.

[5] N. Bartke and Y. A. Hannun, "Bioactive sphingolipids: metabolism and function," Journal of lipid research, vol. 50, pp. S91-S96, 2009.

[6] M. J. Smyth, L. M. Obeid, and Y. A. Hannun, "Ceramide: a novel lipid mediator of apoptosis," Advances in Pharmacology, vol. 41, pp. 133-154, 1997.

[7] A. Morales, H. Lee, F. M. Goñi, R. Kolesnick, and J. C. Fernandez-Checa, "Sphingolipids and cell death," Apoptosis, vol. 12, no. 5, pp. 923-939, 2007.

[8] B. Ogretmen and Y. A. Hannun, "Biologically active sphingolipids in cancer pathogenesis and treatment," Nature Reviews Cancer, vol. 4, no. 8, pp. 604-616, 2004.

[9] S. A. Saddoughi, P. Song, and B. Ogretmen, "Roles of bioactive sphingolipids in cancer biology and therapeutics," Sub-Cellular Biochemistry, vol. 49, pp. 413-440, 2008.

[10] A. Huwiler and U. Zangemeister-Wittke, "Targeting the conversion of ceramide to sphingosine 1-phosphate as a novel strategy for cancer therapy," Critical Reviews in Oncology/Hematology, vol. 63, no. 2, pp. 150-159, 2007.

[11] C. P. Reynolds, B. J. Maurer, and R. N. Kolesnick, "Ceramide synthesis and metabolism as a target for cancer therapy," Cancer Letters, vol. 206, no. 2, pp. 169-180, 2004.

[12] B. J. Pettus, C. E. Chalfant, and Y. A. Hannun, "Ceramide in apoptosis: an overview and current perspectives," Biochimica et Biophysica Acta, vol. 1585, no. 2-3, pp. 114-125, 2002.

[13] Y. A. Hannun and C. Luberto, "Ceramide in the eukaryotic stress response," Trends in Cell Biology, vol. 10, no. 2, pp. 7380, 2000.

[14] C. F. Lin, C. L. Chen, and Y. S. Lin, "Ceramide in apoptotic signaling and anticancer therapy," Current Medicinal Chemistry, vol. 13, no. 14, pp. 1609-1616, 2006.
[15] J. Dhein, H. Walczak, C. Baumler, K. M. Debatin, and P. H. Krammer, "Autocrine T-cell suicide mediated by APO1/(Fas/CD95)," Nature, vol. 373, no. 6513, pp. 438-441, 1995.

[16] L. A. Tartaglia, M. Rothe, Y. F. Hu, and D. V. Goeddel, "Tumor necrosis factor's cytotoxic activity is signaled by the p55 TNF receptor," Cell, vol. 73, no. 2, pp. 213-216, 1993.

[17] J. Kitson, T. Raven, Y. P. Jiang et al., "A death-domaincontaining receptor that mediates apoptosis," Nature, vol. 384, no. 6607, pp. 372-375, 1996.

[18] G. Pan, K. O’Rourke, A. M. Chinnaiyan et al., "The receptor for the cytotoxic ligand TRAIL," Science, vol. 276, no. 5309, pp. 111-113, 1997.

[19] A. Ashkenazi and V. M. Dixit, "Death receptors: signaling and modulation," Science, vol. 281, no. 5381, pp. 1305-1308, 1998.

[20] D. R. Green and J. C. Reed, "Mitochondria and apoptosis," Science, vol. 281, no. 5381, pp. 1309-1312, 1998.

[21] G. Kroemer and J. C. Reed, "Mitochondrial control of cell death," Nature Medicine, vol. 6, no. 5, pp. 513-519, 2000.

[22] J. C. Reed, "Bcl-2 family proteins," Oncogene, vol. 17, no. 25, pp. 3225-3236, 1998.

[23] XU. Luo, I. Budihardjo, H. Zou, C. Slaughter, and X. Wang, "Bid, a $\mathrm{Bcl} 2$ interacting protein, mediates cytochrome c release from mitochondria in response to activation of cell surface death receptors," Cell, vol. 94, no. 4, pp. 481-490, 1998.

[24] N. Zamzami, C. E. Hamel, C. Maisse et al., "Bid acts on the permeability transition pore complex to induce apoptosis," Oncogene, vol. 19, no. 54, pp. 6342-6350, 2000.

[25] C. Xu, B. Bailly-Maitre, and J. C. Reed, "Endoplasmic reticulum stress: cell life and death decisions," Journal of Clinical Investigation, vol. 115, no. 10, pp. 2656-2664, 2005.

[26] J. Wu and R. J. Kaufman, "From acute ER stress to physiological roles of the unfolded protein response," Cell Death and Differentiation, vol. 13, no. 3, pp. 374-384, 2006.

[27] D. G. Breckenridge, M. Germain, J. P. Mathai, M. Nguyen, and G. C. Shore, "Regulation of apoptosis by endoplasmic reticulum pathways," Oncogene, vol. 22, no. 53, pp. 86088618, 2003.

[28] J. Matsukawa, A. Matsuzawa, K. Takeda, and H. Ichijo, "The ASK1-MAP kinase cascades in mammalian stress response," Journal of Biochemistry, vol. 136, no. 3, pp. 261-265, 2004.

[29] H. Nishitoh, A. Matsuzawa, K. Tobiume et al., "ASK1 is essential for endoplasmic reticulum stress-induced neuronal cell death triggered by expanded polyglutamine repeats," Genes and Development, vol. 16, no. 11, pp. 1345-1355, 2002.

[30] M. K. Dahmer, "Caspases-2, -3 , and -7 are involved in thapsigargin-induced apoptosis of SH-SY5Y neuroblastoma cells," Journal of Neuroscience Research, vol. 80, no. 4, pp. 576583, 2005.

[31] H. H. Cheung, N. Lynn Kelly, P. Liston, and R. G. Korneluk, "Involvement of caspase- 2 and caspase- 9 in endoplasmic reticulum stress-induced apoptosis: a role for the IAPs," Experimental Cell Research, vol. 312, no. 12, pp. 2347-2357, 2006.

[32] J. P. Upton, K. Austgen, M. Nishino et al., "Caspase-2 cleavage of BID is a critical apoptotic signal downstream of endoplasmic reticulum stress," Molecular and Cellular Biology, vol. 28, no. 12, pp. 3943-3951, 2008.

[33] K. D. McCullough, J. L. Martindale, L. O. Klotz, T. Y. Aw, and N. J. Holbrook, "Gadd153 sensitizes cells to endoplasmic reticulum stress by down-regulating $\mathrm{Bc} 12$ and perturbing the cellular redox state," Molecular and Cellular Biology, vol. 21, no. 4, pp. 1249-1259, 2001. 
[34] Y. Tan, N. Dourdin, C. Wu, T. de Veyra, J. S. Elce, and P. A. Greer, "Ubiquitous calpains promote caspase-12 and JNK activation during endoplasmic reticulum stress-induced apoptosis," Journal of Biological Chemistry, vol. 281, no. 23, pp. 16016-16024, 2006.

[35] K. F. Ferri and G. Kroemer, "Organelle-specific initiation of cell death pathways," Nature Cell Biology, vol. 3, no. 11, pp. E255-E263, 2001.

[36] M. E. Guicciardi, M. Leist, and G. J. Gores, "Lysosomes in cell death," Oncogene, vol. 23, no. 16, pp. 2881-2890, 2004.

[37] G. Kroemer and M. Jäättelä, "Lysosomes and autophagy in cell death control," Nature Reviews Cancer, vol. 5, no. 11, pp. 886-897, 2005.

[38] C. E. Chwieralski, T. Welte, and F. Bühling, "Cathepsinregulated apoptosis," Apoptosis, vol. 11, no. 2, pp. 143-149, 2006.

[39] N. Marchesini and Y. A. Hannun, "Acid and neutral sphingomyelinases: roles and mechanisms of regulation," Biochemistry and Cell Biology, vol. 82, no. 1, pp. 27-44, 2004.

[40] R. J. Perry and N. D. Ridgway, "Molecular mechanisms and regulation of ceramide transport," Biochimica et Biophysica Acta, vol. 1734, no. 3, pp. 220-234, 2005.

[41] G. F. Nixon, "Sphingolipids in inflammation: pathological implications and potential therapeutic targets," British Journal of Pharmacology, vol. 158, no. 4, pp. 982-993, 2009.

[42] S. Schiffmann, J. Sandner, R. Schmidt et al., "The selective COX-2 inhibitor celecoxib modulates sphingolipid synthesis," Journal of Lipid Research, vol. 50, no. 1, pp. 32-40, 2009.

[43] T. Ariga, W. D. Jarvis, and R. K. Yu, "Role of sphingolipidmediated cell death in neurodegenerative diseases," Journal of Lipid Research, vol. 39, no. 1, pp. 1-16, 1998.

[44] C. Grullich, M. C. Sullards, Z. Fuks, A. H. Merrill Jr., and R. Kolesnick, "CD95(Fas/APO-1) signals ceramide generation independent of the effector stage of apoptosis," Journal of Biological Chemistry, vol. 275, no. 12, pp. 8650-8656, 2000.

[45] L. M. Obeid, C. M. Linardic, L. A. Karolak, and Y. A. Hannun, "Programmed cell death induced by ceramide," Science, vol. 259, no. 5102, pp. 1769-1771, 1993.

[46] K. Hofmann and V. M. Dixit, "Ceramide in apoptosis—does it really matter?" Trends in Biochemical Sciences, vol. 23, no. 10, pp. 374-377, 1998.

[47] R. Kolesnick and Y. A. Hannun, "Ceramide and apoptosis," Trends in Biochemical Sciences, vol. 24, pp. 224-227, 1999.

[48] J. D. Watts, R. Aebersold, A. J. Polverino, S. D. Patterson, and M. Gu, "Ceramide second messengers and ceramide assays," Trends in Biochemical Sciences, vol. 24, no. 6, article 228, 1999.

[49] R. N. Kolesnick, A. Haimovitz-Friedman, and Z. Fuks, "The sphingomyelin signal transduction pathway mediates apoptosis for tumor necrosis factor, Fas, and ionizing radiation," Biochemistry and Cell Biology, vol. 72, no. 11-12, pp. 471-474, 1994.

[50] R. Schwandner, K. Wiegmann, K. Bernardo, D. Kreder, and M. Krönke, "TNF receptor death domain-associated proteins TRADD and FADD signal activation of acid sphingomyelinase," Journal of Biological Chemistry, vol. 273, no. 10, pp. 5916-5922, 1998.

[51] T. Lin, L. Genestier, M. J. Pinkoski et al., "Role of acidic sphingomyelinase in Fas/CD95-mediated cell death," Journal of Biological Chemistry, vol. 275, no. 12, pp. 8657-8663, 2000.

[52] C. García-Ruiz, A. Colell, M. Mari et al., "Defective TNF$\alpha$-mediated hepatocellular apoptosis and liver damage in acidic sphingomyelinase knockout mice," Journal of Clinical Investigation, vol. 111, no. 2, pp. 197-208, 2003.
[53] B. Ségui, O. Cuvillier, S. Adam-Klages et al., "Involvement of FAN in TNF-induced apoptosis," Journal of Clinical Investigation, vol. 108, no. 1, pp. 143-151, 2001.

[54] R. N. Kolesnick, F. M. Goñi, and A. Alonso, "Compartmentalization of ceramide signaling: physical foundations and biological effects," Journal of Cellular Physiology, vol. 184, no. 3, pp. 285-300, 2000.

[55] A. Bielawska, H. M. Crane, D. Liotta, L. M. Obeid, and Y. A. Hannun, "Selectivity of ceramide-mediated biology. Lack of activity of erythro-dihydroceramide," Journal of Biological Chemistry, vol. 268, no. 35, pp. 26226-26232, 1993.

[56] M. J. Smyth, D. K. Perry, J. Zhang, G. G. Poirier, Y. A. Hannun, and L. M. Obeid, "prICE: a downstream target for ceramide-induced apoptosis and for the inhibitory action of Bcl-2," Biochemical Journal, vol. 316, no. 1, pp. 25-28, 1996.

[57] S. J. Martin, D. D. Newmeyer, S. Mathias et al., "Cell-free reconstitution of Fas-, UV radiation- and ceramide-induced apoptosis," EMBO Journal, vol. 14, no. 21, pp. 5191-5200, 1995.

[58] Y. A. Hannun and C. M. Linardic, "Sphingolipid breakdown products: anti-proliferative and tumor-suppressor lipids," Biochimica et Biophysica Acta, vol. 1154, no. 3-4, pp. 223-236, 1993.

[59] A. F. Nica, C. T. Chun, J. C. Watt et al., "Ceramide promotes apoptosis in chronic myelogenous leukemia-derived K562 cells by a mechanism involving caspase- 8 and JNK," Cell Cycle, vol. 7, no. 21, pp. 3362-3370, 2008.

[60] V. Maguer-Satta, S. Burl, L. Liu et al., "BCR-ABL accelerates C2-ceramide-induced apoptosis," Oncogene, vol. 16, no. 2, pp. 237-248, 1998.

[61] X. Liu, L. Ryland, J. Yang et al., "Targeting of survivin by nanoliposomal ceramide induces complete remission in a rat model of NK-LGL leukemia," Blood, vol. 16, no. 20, pp. 41924201, 2010.

[62] B. Ogretmen, B. J. Pettus, M. J. Rossi et al., "Biochemical mechanisms of the generation of endogenous long chain ceramide in response to exogenous short chain ceramide in the A549 human lung adenocarcinoma cell line. Role for endogenous ceramide in mediating the action of exogenous ceramide," Journal of Biological Chemistry, vol. 277, no. 15, pp. 12960-12969, 2002.

[63] S. Karahatay, K. Thomas, S. Koybasi et al., "Clinical relevance of ceramide metabolism in the pathogenesis of human head and neck squamous cell carcinoma (HNSCC): attenuation of C-ceramide in HNSCC tumors correlates with lymphovascular invasion and nodal metastasis," Cancer Letters, vol. 256, no. 1, pp. 101-111, 2007.

[64] S. Koybasi, C. E. Senkal, K. Sundararaj et al., "Defects in cell growth regulation by $\mathrm{C}$-ceramide and longevity assurance gene 1 in human head and neck squamous cell carcinomas," Journal of Biological Chemistry, vol. 279, no. 43, pp. 4431144319, 2004.

[65] C. E. Senkal, S. Ponnusamy, M. J. Rossi et al., "Role of human longevity assurance gene 1 and C-ceramide in chemotherapy-induced cell death in human head and neck squamous cell carcinomas," Molecular Cancer Therapeutics, vol. 6, no. 2, pp. 712-722, 2007.

[66] C. E. Senkal, S. Ponnusamy, J. Bielawski, Y. A. Hannun, and B. Ogretmen, "Antiapoptotic roles of ceramide-synthase-6generated C- ceramide via selective regulation of the ATF6/ CHOP arm of ER-stress-response pathways," FASEB Journal, vol. 24, no. 1, pp. 296-308, 2010. 
[67] A. Srinivasan, L. M. Foster, M. P. Testa et al., "Bcl-2 expression in neural cells blocks activation of ICE/CED-3 family proteases during apoptosis," Journal of Neuroscience, vol. 16, no. 18, pp. 5654-5660, 1996.

[68] C. García-Ruiz, A. Colell, M. Marí, A. Morales, and J. C. Fernández-Checa, "Direct effect of ceramide on the mitochondrial electron transport chain leads to generation of reactive oxygen species: role of mitochondrial glutathione," Journal of Biological Chemistry, vol. 272, no. 17, pp. 1136911377, 1997.

[69] T. I. Gudz, K. Y. Tserng, and C. L. Hoppel, "Direct inhibition of mitochondrial respiratory chain complex III by cellpermeable ceramide," Journal of Biological Chemistry, vol. 272, no. 39, pp. 24154-24158, 1997.

[70] A. Quillet-Mary, J. P. Jaffrézou, V. Mansat, C. Bordier, J. Naval, and G. Laurent, "Implication of mitochondrial hydrogen peroxide generation in ceramide-induced apoptosis," Journal of Biological Chemistry, vol. 272, no. 34, pp. 2138821395, 1997.

[71] L. J. Siskind, R. N. Kolesnick, and M. Colombini, "Ceramide channels increase the permeability of the mitochondrial outer membrane to small proteins," Journal of Biological Chemistry, vol. 277, no. 30, pp. 26796-26803, 2002.

[72] L. J. Siskind, R. N. Kolesnick, and M. Colombini, "Ceramide forms channels in mitochondrial outer membranes at physiologically relevant concentrations," Mitochondrion, vol. 6, no. 3, pp. 118-125, 2006.

[73] H. Birbes, C. Luberto, Y. T. Hsu, S. El Bawab, Y. A. Hannun, and L. M. Obeid, "A mitochondrial pool of sphingomyelin is involved in TNF $\alpha$-induced Bax translocation to mitochondria," Biochemical Journal, vol. 386, no. 3, pp. 445-451, 2005.

[74] S. El Bawab, P. Roddy, T. Qian, A. Bielawska, J. J. Lemasters, and Y. A. Hannun, "Molecular cloning and characterization of a human mitochondrial ceramidase," Journal of Biological Chemistry, vol. 275, no. 28, pp. 21508-21513, 2000.

[75] C. Bionda, J. Portoukalian, D. Schmitt, C. RodriguezLafrasse, and D. Ardail, "Subcellular compartmentalization of ceramide metabolism: MAM (mitochondria-associated membrane) and/or mitochondria?" Biochemical Journal, vol. 382, no. 2, pp. 527-533, 2004.

[76] H. Birbes, S. El Bawab, Y. A. Hannun, and L. M. Obeid, "Selective hydrolysis of a mitochondrial pool of sphingomyelin induces apoptosis," FASEB Journal, vol. 15, no. 14, pp. 2669-2679, 2001.

[77] C. F. Lin, C. L. Chen, W. T. Chang et al., "Bcl-2 rescues ceramide- and etoposide-induced mitochondrial apoptosis through blockage of caspase-2 activation," Journal of Biological Chemistry, vol. 280, no. 25, pp. 23758-23765, 2005.

[78] M. Fillet, M. Bentires-Alj, V. Deregowski et al., "Mechanisms involved in exogenous C2- and C6-ceramide-induced cancer cell toxicity," Biochemical Pharmacology, vol. 65, no. 10, pp. 1633-1642, 2003.

[79] C. F. Lin, C. L. Chen, W. T. Chang et al., "Sequential caspase2 and caspase- 8 activation upstream of mitochondria during ceramide- and etoposide-induced apoptosis," Journal of Biological Chemistry, vol. 279, no. 39, pp. 40755-40761, 2004.

[80] C. F. Lin, C. L. Chen, C. W. Chiang, M. S. Jan, W. C. Huang, and Y. S. Lin, "GSK- $3 \beta$ acts downstream of PP2A and the PI 3-kinase-Akt pathway, and upstream of caspase-2 in ceramide-induced mitochondrial apoptosis," Journal of Cell Science, vol. 120, no. 16, pp. 2935-2943, 2007.

[81] K. Hanada, K. Kumagai, S. Yasuda et al., "Molecular machinery for non-vesicular trafficking of ceramide," Nature, vol. 426, no. 6968, pp. 803-809, 2003.
[82] S. D. Spassieva, T. D. Mullen, D. M. Townsend, and L. M. Obeid, "Disruption of ceramide synthesis by CerS2 downregulation leads to autophagy and the unfolded protein response," Biochemical Journal, vol. 424, no. 2, pp. 273-283, 2009.

[83] A. Carracedo, M. Lorente, A. Egia et al., "The stressregulated protein $\mathrm{p} 8$ mediates cannabinoid-induced apoptosis of tumor cells," Cancer Cell, vol. 9, no. 4, pp. 301-312, 2006.

[84] M. A. Park, G. Zhang, A. P. Martin et al., "Vorinostat and sorafenib increase ER stress, autophagy and apoptosis via ceramide-dependent CD95 and PERK activation," Cancer Biology and Therapy, vol. 7, no. 10, pp. 1648-1662, 2008.

[85] C. Swanton, M. Marani, O. Pardo et al., "Regulators of mitotic arrest and ceramide metabolism are determinants of sensitivity to paclitaxel and other chemotherapeutic drugs," Cancer Cell, vol. 11, no. 6, pp. 498-512, 2007.

[86] R. Kolesnick, D. Altieri, and Z. Fuks, "A CERTain role for ceramide in taxane-induced cell death," Cancer Cell, vol. 11, no. 6, pp. 473-475, 2007.

[87] C. L. Chen, C. F. Lin, W. T. Chang, W. C. Huang, C. F. Teng, and Y. S. Lin, "Ceramide induces p38 MAPK and JNK activation through a mechanism involving a thioredoxininteracting protein-mediated pathway," Blood, vol. 111, no. 8, pp. 4365-4374, 2008.

[88] M. Verheij, R. Bose, X. H. Lin et al., "Requirement for ceramide-initiated SAPK/JNK signalling in stress-induced apoptosis," Nature, vol. 380, no. 6569, pp. 75-79, 1996.

[89] D. L. Eizirik, A. K. Cardozo, and M. Cnop, "The role for endoplasmic reticulum stress in diabetes mellitus," Endocrine Reviews, vol. 29, no. 1, pp. 42-61, 2008.

[90] M. Flamment, H. L. Kammoun, I. Hainault, P. Ferré, and F. Foufelle, "Endoplasmic reticulum stress: a new actor in the development of hepatic steatosis," Current Opinion in Lipidology, vol. 21, no. 3, pp. 239-246, 2010.

[91] I. Tabas, "The role of endoplasmic reticulum stress in the progression of atherosclerosis," Circulation Research, vol. 107, pp. 839-850, 2010.

[92] S. A. Summers, "Ceramides in insulin resistance and lipotoxicity," Progress in Lipid Research, vol. 45, no. 1, pp. 42-72, 2006.

[93] W. L. Holland, J. T. Brozinick, L. P. Wang et al., "Inhibition of ceramide synthesis ameliorates glucocorticoid-, saturatedfat-, and obesity-induced insulin resistance," Cell Metabolism, vol. 5, no. 3, pp. 167-179, 2007.

[94] M. Shimabukuro, Y. T. Zhou, M. Levi, and R. H. Unger, "Fatty acid-induced $\beta$ cell apoptosis: a link between obesity and diabetes," Proceedings of the National Academy of Sciences of the United States of America, vol. 95, no. 5, pp. 2498-2502, 1998.

[95] S. Patil, J. Melrose, and C. Chan, "Involvement of astroglial ceramide in palmitic acid-induced Alzheimer-like changes in primary neurons," European Journal of Neuroscience, vol. 26, no. 8, pp. 2131-2141, 2007.

[96] Y. Wei, D. Wang, F. Topczewski, and M. J. Pagliassotti, "Saturated fatty acids induce endoplasmic reticulum stress and apoptosis independently of ceramide in liver cells," American Journal of Physiology-Endocrinology and Metabolism, vol. 291, no. 2, pp. E275-E281, 2006.

[97] M. Heinrich, J. Neumeyer, M. Jakob et al., "Cathepsin D links TNF-induced acid sphingomyelinase to Bid-mediated caspase- 9 and -3 activation," Cell Death and Differentiation, vol. 11 , no. 5 , pp. 550-563, 2004. 
[98] D. de Stefanis, P. Reffo, G. Bonelli et al., "Increase in ceramide level alters the lysosomal targeting of cathepsin D prior to onset of apoptosis in HT-29 colon cancer cells," Biological Chemistry, vol. 383, no. 6, pp. 989-999, 2002.

[99] C. A. Dumitru, I. E. Sandalcioglu, M. Wagner, M. Weller, and E. Gulbins, "Lysosomal ceramide mediates gemcitabineinduced death of glioma cells," Journal of Molecular Medicine, vol. 87, no. 11, pp. 1123-1132, 2009.

[100] M. Heinrich, M. Wickel, S. Winoto-Morbach et al., "Ceramide as an activator lipid of cathepsin D," Advances in Experimental Medicine and Biology, vol. 477, pp. 305-315, 2000.

[101] M. Heinrich, M. Wickel, W. Schneider-Brachert et al., "Cathepsin D targeted by acid sphingomyelinase-derived ceramide," EMBO Journal, vol. 18, no. 19, pp. 5252-5263, 1999.

[102] A. E. Feldstein, N. W. Werneburg, Z. Li, S. F. Bronk, and G. J. Gores, "Bax inhibition protects against free fatty acidinduced lysosomal permeabilization," American Journal of Physiology-Gastrointestinal and Liver Physiology, vol. 290, no. 6, pp. G1339-G1346, 2006.

[103] Y. Y. Liu, T. Y. Han, A. E. Giuliano, and M. C. Cabot, "Expression of glucosylceramide synthase, converting ceramide to glucosylceramide, confers adriamycin resistance in human breast cancer cells," Journal of Biological Chemistry, vol. 274, no. 2, pp. 1140-1146, 1999.

[104] V. Gouazé, J. Y. Yu, R. J. Bleicher et al., "Overexpression of glucosylceramide synthase and P-glycoprotein in cancer cells selected for resistance to natural product chemotherapy," Molecular Cancer Therapeutics, vol. 3, no. 5, pp. 633-639, 2004.

[105] M. Itoh, T. Kitano, M. Watanabe et al., "Possible role of ceramide as an indicator of chemoresistance: decrease of the ceramide content via activation of glucosylceramide synthase and sphingomyelin synthase in chemoresistant leukemia," Clinical Cancer Research, vol. 9, no. 1 I, pp. 415-423, 2003.

[106] Y. Y. Liu, T. Y. Han, A. E. Giuliano, N. Hansen, and M. C. Cabot, "Uncoupling ceramide glycosylation by transfection of glucosylceramide synthase antisense reverses adriamycin resistance," Journal of Biological Chemistry, vol. 275, no. 10, pp. 7138-7143, 2000.

[107] V. Gouazé, Y. Y. Liu, C. S. Prickett, J. Y. Yu, A. E. Giuliano, and M. C. Cabot, "Glucosylceramide synthase blockade downregulates P-glycoprotein and resensitizes multidrug-resistant breast cancer cells to anticancer drugs," Cancer Research, vol. 65, no. 9, pp. 3861-3867, 2005.

[108] G. A. Patwardhan, Q. J. Zhang, D. Yin et al., "A new mixedbackbone oligonucleotide against glucosylceramide synthase sensitizes multidrug-resistant tumors to apoptosis," PLoS ONE, vol. 4, no. 9, article e6938, 2009.

[109] Y.-Y. Liu, V. Gupta, G. A. Patwardhan et al., "Glucosylceramide synthase upregulates MDR1 expression in the regulation of cancer drug resistance through $\mathrm{cSrc}$ and $\beta$ catenin signaling," Molecular Cancer, vol. 9, article 145, 2010.

[110] S. di Bartolomeo and A. Spinedi, "Differential chemosensitizing effect of two glucosylceramide synthase inhibitors in hepatoma cells," Biochemical and Biophysical Research Communications, vol. 288, no. 1, pp. 269-274, 2001.

[111] P. Xie, Y. F. Shen, Y. P. Shi et al., "Overexpression of glucosylceramide synthase in associated with multidrug resistance of leukemia cells," Leukemia Research, vol. 32, no. 3, pp. 475-480, 2008.
[112] A. F. Saad, W. D. Meacham, A. Bai et al., "The functional effects of acid ceramidase overexpression in prostate cancer progression and resistance to chemotherapy," Cancer Biology and Therapy, vol. 6, no. 9, pp. 1455-1460, 2007.

[113] A. Morales, R. París, A. Villanueva, L. Llacuna, C. GarcíaRuiz, and J. C. Fernández-Checa, "Pharmacological inhibition or small interfering RNA targeting acid ceramidase sensitizes hepatoma cells to chemotherapy and reduces tumor growth in vivo," Oncogene, vol. 26, no. 6, pp. 905-916, 2007.

[114] G. Illuzzi, C. Bernacchioni, M. Aureli et al., "Sphingosine kinase mediates resistance to the synthetic retinoid $\mathrm{N}-(4-$ hydroxyphenyl)retinamide in human ovarian cancer cells," Journal of Biological Chemistry, vol. 285, no. 24, pp. 1859418602, 2010.

[115] E. Bonhoure, D. Pchejetski, N. Aouali et al., "Overcoming MDR-associated chemoresistance in HL-60 acute myeloid leukemia cells by targeting shingosine kinase-1," Leukemia, vol. 20, no. 1, pp. 95-102, 2006.

[116] J. Guillermet-Guibert, L. Davenne, D. Pchejetski et al., "Targeting the sphingolipid metabolism to defeat pancreatic cancer cell resistance to the chemotherapeutic gemcitabine drug," Molecular Cancer Therapeutics, vol. 8, no. 4, pp. 809820, 2009.

[117] S. Sobue, S. Nemoto, M. Murakami et al., "Implications of sphingosine kinase 1 expression level for the cellular sphingolipid rheostat: relevance as a marker for daunorubicin sensitivity of leukemia cells," International Journal of Hematology, vol. 87, no. 3, pp. 266-275, 2008.

[118] Y. Akao, Y. Banno, Y. Nakagawa et al., "High expression of sphingosine kinase 1 and $\mathrm{S} 1 \mathrm{P}$ receptors in chemotherapyresistant prostate cancer PC3 cells and their camptothecininduced up-regulation," Biochemical and Biophysical Research Communications, vol. 342, no. 4, pp. 1284-1290, 2006.

[119] S. Nemoto, M. Nakamura, Y. Osawa et al., "Sphingosine kinase isoforms regulate oxaliplatin sensitivity of human colon cancer cells through ceramide accumulation and Akt activation," Journal of Biological Chemistry, vol. 284, no. 16, pp. 10422-10432, 2009.

[120] G. Grammatikos, V. Teichgräber, A. Carpinteiro et al., "Overexpression of acid sphingomyelinase sensitizes glioma cells to chemotherapy," Antioxidants and Redox Signaling, vol. 9, no. 9, pp. 1449-1456, 2007.

[121] J. Min, P. P. van Veldhoven, L. Zhang, M. H. Hanigan, H. Alexander, and S. Alexander, "Sphingosine-1-phosphate lyase regulates sensitivity of human cells to select chemotherapy drugs in a p38-dependent manner," Molecular Cancer Research, vol. 3, no. 5, pp. 287-296, 2005.

[122] M. M. Gottesman, "Mechanisms of cancer drug resistance," Annual Review of Medicine, vol. 53, pp. 615-627, 2002.

[123] P. Giménez-Bonafé, A. Tortosa, and R. Pérez-Tomás, “Overcoming drug resistance by enhancing apoptosis of tumor cells," Current Cancer Drug Targets, vol. 9, no. 3, pp. 320-340, 2009.

[124] S. G. Lutzker and A. J. Levine, "Apoptosis and cancer chemotherapy," Cancer Treatment and Research, vol. 87, pp. 345-356, 1996.

[125] A. Senchenkov, D. A. Litvak, and M. C. Cabot, "Targeting ceramide metabolism - a strategy for overcoming drug resistance," Journal of the National Cancer Institute, vol. 93, no. 5, pp. 347-357, 2001. 
[126] Y. Lavie, H. T. Cao, S. L. Bursten, A. E. Giuliano, and M. C. Cabot, "Accumulation of glucosylceramides in multidrugresistant cancer cells," Journal of Biological Chemistry, vol. 271, no. 32, pp. 19530-19536, 1996.

[127] A. Lucci, W. I. Cho, T. Y. Han, A. E. Giuliano, D. L. Morton, and M. C. Cabot, "Glucosylceramide: a marker for multipledrug resistant cancers," Anticancer Research, vol. 18, no. 1, pp. 475-480, 1998.

[128] H. Morjani, N. Aouali, R. Belhoussine, R. J. Veldman, T. Levade, and M. Manfait, "Elevation of glucosylceramide in multidrug-resistant cancer cells and accumulation in cytoplasmic droplets," International Journal of Cancer, vol. 94, no. 2, pp. 157-165, 2001.

[129] R. J. Veldman, K. Klappe, J. Hinrichs et al., "Altered sphingolipid metabolism in multidrug-resistant ovarian cancer cells is due to uncoupling of glycolipid biosynthesis in the Golgi apparatus," The FASEB Journal, vol. 16, no. 9, pp. 11111113, 2002.

[130] V. Gouazé-Andersson, J. Y. Yu, A. J. Kreitenberg, A. Bielawska, A. E. Giuliano, and M. C. Cabot, "Ceramide and glucosylceramide upregulate expression of the multidrug resistance gene MDR1 in cancer cells," Biochimica et Biophysica Acta, vol. 1771, no. 12, pp. 1407-1417, 2007.

[131] K. Ueda, M. M. Cornwell, M. M. Gottesman et al., "The mdrl gene, responsible for multidrug-resistance, codes for Pglycoprotein," Biochemical and Biophysical Research Communications, vol. 141, no. 3, pp. 956-962, 1986.

[132] M. M. Gottesman, I. Pastan, and S. V. Ambudkar, "Pglycoprotein and multidrug resistance," Current Opinion in Genetics and Development, vol. 6, no. 5, pp. 610-617, 1996.

[133] G. Bradley and V. Ling, "P-glycoprotein, multidrug resistance and tumor progression," Cancer and Metastasis Reviews, vol. 13, no. 2, pp. 223-233, 1994.

[134] R. J. Veldman, A. Mita, O. Cuvillier et al., "The absence of functional glucosylceramide synthase does not sensitize melanoma cells for anticancer drugs," FASEB Journal, vol. 17, no. 9, pp. 1144-1146, 2003.

[135] N. S. Radin, "Chemotherapy by slowing glucosphingolipid synthesis," Biochemical Pharmacology, vol. 57, no. 6, pp. 589$595,1999$.

[136] J.-I. Inokuchi, M. Jimbo, K. Momasaki, H. Shimeno, A. Nagamatsu, and N. S. Radin, "Inhibition of experimental metastasis of murine Lewis lung carcinoma by an inhibitor of glycosylceramide synthase and its possible mechanism of action," Cancer Research, vol. 50, no. 20, pp. 6731-6737, 1990.

[137] C. Mao and L. M. Obeid, "Ceramidases: regulators of cellular responses mediated by ceramide, sphingosine, and sphingosine-1-phosphate," Biochimica et Biophysica Acta, vol. 1781, no. 9, pp. 424-434, 2008.

[138] R. S. Seelan, C. Qian, A. Yokomizo, D. G. Bostwick, D. I. Smith, and W. Liu, "Human acid ceramidase is overexpressed but not mutated in prostate cancer," Genes Chromosomes and Cancer, vol. 29, no. 2, pp. 137-146, 2000.

[139] L. Samsel, G. Zaidel, H. M. Drumgoole et al., "The ceramide analog, B13, induces apoptosis in prostate cancer cell lines and inhibits tumor growth in prostate cancer xenografts," Prostate, vol. 58, no. 4, pp. 382-393, 2004.

[140] D. H. Holman, L. S. Turner, A. El-Zawahry et al., "Lysosomotropic acid ceramidase inhibitor induces apoptosis in prostate cancer cells," Cancer Chemotherapy and Pharmacology, vol. 61, no. 2, pp. 231-242, 2008.
[141] M. Selzner, A. Bielawska, M. A. Morse et al., "Induction of apoptotic cell death and prevention of tumor growth by ceramide analogues in metastatic human colon cancer," Cancer Research, vol. 61, no. 3, pp. 1233-1240, 2001.

[142] A. F. Rénert, P. Leprince, M. Dieu et al., "The proapoptotic C16-ceramide-dependent pathway requires the deathpromoting factor Btf in colon adenocarcinoma cells," Journal of Proteome Research, vol. 8, no. 10, pp. 4810-4822, 2009.

[143] A. Strelow, K. Bernardo, S. Adam-Klages et al., "Overexpression of acid ceramidase protects from tumor necrosis factorinduced cell death," Journal of Experimental Medicine, vol. 192, no. 5, pp. 601-611, 2000.

[144] Y. Osawa, H. Uchinami, J. Bielawski, R. F. Schwabe, Y. A. Hannun, and D. A. Brenner, "Roles for C-ceramide and sphingosine 1-phosphate in regulating hepatocyte apoptosis in response to tumor necrosis factor- $\alpha$," Journal of Biological Chemistry, vol. 280, no. 30, pp. 27879-27887, 2005.

[145] R. Xu, J. Jin, W. Hu et al., "Golgi alkaline ceramidase regulates cell proliferation and survival by controlling levels of sphingosine and S1P," FASEB Journal, vol. 20, no. 11, pp. 1813-1825, 2006.

[146] W. Hu, R. Xu, W. Sun et al., "Alkaline ceramidase 3 (ACER3) hydrolyzes unsaturated long-chain ceramides, and its downregulation inhibits both cell proliferation and apoptosis," Journal of Biological Chemistry, vol. 285, no. 11, pp. 79647976, 2010.

[147] H. Liu, R. E. Toman, S. K. Goparaju et al., "Sphingosine kinase type 2 is a putative $\mathrm{BH}$-only protein that induces apoptosis," Journal of Biological Chemistry, vol. 278, no. 41, pp. 40330-40336, 2003.

[148] M. Maceyka, H. Sankala, N. C. Hait et al., "SphK1 and SphK2, sphingosine kinase isoenzymes with opposing functions in sphingolipid metabolism," Journal of Biological Chemistry, vol. 280, no. 44, pp. 37118-37129, 2005.

[149] K. J. French, Y. Zhuang, L. W. Maines et al., "Pharmacology and antitumor activity of ABC294640, a selective inhibitor of sphingosine kinase-2," Journal of Pharmacology and Experimental Therapeutics, vol. 333, no. 1, pp. 129-139, 2010.

[150] E. Le Scolan, D. Pchejetski, Y. Banno et al., "Overexpression of sphingosine kinase 1 is an oncogenic event in erythroleukemic progression," Blood, vol. 106, no. 5, pp. $1808-$ 1816, 2005.

[151] Q. F. Li, W. R. Huang, H. F. Duan, H. Wang, C. T. Wu, and L. S. Wang, "Sphingosine kinase-1 mediates BCR/ABL-induced upregulation of Mcl-1 in chronic myeloid leukemia cells," Oncogene, vol. 26, no. 57, pp. 7904-7908, 2007.

[152] E. Bonhoure, A. Lauret, D. J. Barnes et al., "Sphingosine kinase-1 is a downstream regulator of imatinib-induced apoptosis in chronic myeloid leukemia cells," Leukemia, vol. 22, no. 5, pp. 971-979, 2008.

[153] S. Sobue, T. Iwasaki, C. Sugisaki et al., "Quantitative RT-PCR analysis of sphingolipid metabolic enzymes in acute leukemia and myelodysplastic syndromes," Leukemia, vol. 20, no. 11, pp. 2042-2046, 2006.

[154] B. S. Paugh, S. W. Paugh, L. Bryan et al., "EGF regulates plasminogen activator inhibitor-1 (PAI-1) by a pathway involving $\mathrm{c}-\mathrm{Src}, \mathrm{PKC} \delta$, and sphingosine kinase 1 in glioblastoma cells," FASEB Journal, vol. 22, no. 2, pp. 455-465, 2008.

[155] P. Xia, J. R. Gamble, L. Wang et al., "An oncogenic role of sphingosine kinase," Current Biology, vol. 10, no. 23, pp. 1527-1530, 2000. 
[156] X. Shu, W. Wu, R. D. Mosteller, and D. Broek, "Sphingosine kinase mediates vascular endothelial growth factor-induced activation of ras and mitogen-activated protein kinases," Molecular and Cellular Biology, vol. 22, no. 22, pp. 7758-7768, 2002.

[157] K. J. French, R. S. Schrecengost, B. D. Lee et al., "Discovery and evaluation of inhibitors of human sphingosine kinase," Cancer Research, vol. 63, no. 18, pp. 5962-5969, 2003.

[158] K. R. Johnson, K. Y. Johnson, H. G. Crellin et al., "Immunohistochemical distribution of sphinqosine kinase 1 in normal and tumor lung tissue," Journal of Histochemistry and Cytochemistry, vol. 53, no. 9, pp. 1159-1166, 2005.

[159] M. Kohno, M. Momoi, M. L. Oo et al., "Intracellular role for sphingosine kinase 1 in intestinal adenoma cell proliferation," Molecular and Cellular Biology, vol. 26, no. 19, pp. 7211-7223, 2006.

[160] S. E. Schnitzer, A. Weigert, J. Zhou, and B. Brüne, "Hypoxia enhances sphingosine kinase 2 activity and provokes sphingosine-1-phosphate-mediated chemoresistance in A549 lung cancer cells," Molecular Cancer Research, vol. 7, no. 3, pp. 393-401, 2009.

[161] Y. Zhang, P. Mattjus, P. C. Schmidt et al., "Involvement of the acid sphingomyelinase pathway in UVA-induced apoptosis," Journal of Biological Chemistry, vol. 276, no. 15, pp. 1177511782, 2001.

[162] P. Santana, L. A. Peña, A. Haimovitz-Friedman et al., "Acid sphingomyelinase-deficient human lymphoblasts and mice are defective in radiation-induced apoptosis," Cell, vol. 86, no. 2, pp. 189-199, 1996.

[163] A. Carpinteiro, C. Dumitru, M. Schenck, and E. Gulbins, "Ceramide-induced cell death in malignant cells," Cancer Letters, vol. 264, no. 1, pp. 1-10, 2008.

[164] E. L. Smith and E. H. Schuchman, "The unexpected role of acid sphingomyelinase in cell death and the pathophysiology of common diseases," FASEB Journal, vol. 22, no. 10, pp. 3419-3431, 2008.

[165] B. Stancevic and R. Kolesnick, "Ceramide-rich platforms in transmembrane signaling," FEBS Letters, vol. 584, no. 9, pp. 1728-1740, 2010.

[166] J. A. Rotolo, J. Zhang, M. Donepudi, H. Lee, Z. Fuks, and R. Kolesnick, "Caspase-dependent and -independent activation of acid sphingomyelinase signaling," Journal of Biological Chemistry, vol. 280, no. 28, pp. 26425-26434, 2005.

[167] X. Liang and Y. Huang, "Physical state changes of membrane lipids in human lung adenocarcinoma A549 cells and their resistance to cisplatin," International Journal of Biochemistry and Cell Biology, vol. 34, no. 10, pp. 1248-1255, 2002.

[168] O. Cuvillier and T. Levade, "Sphingosine 1-phosphate antagonizes apoptosis of human leukemia cells by inhibiting release of cytochrome $\mathrm{c}$ and Smac/DIABLO from mitochondria," Blood, vol. 98, no. 9, pp. 2828-2836, 2001.

[169] B. Oskouian, P. Soonyakumaran, A. D. Borowsky et al., "Sphingosine-1-phosphate lyase potentiates apoptosis via p53- and p38-dependent pathways and is down-regulated in colon cancer," Proceedings of the National Academy of Sciences of the United States of America, vol. 103, no. 46, pp. 1738417389, 2006.

[170] U. Reiss, B. Oskouian, J. Zhou et al., "Sphingosine-phosphate lyase enhances stress-induced ceramide generation and apoptosis," Journal of Biological Chemistry, vol. 279, no. 2, pp. 1281-1290, 2004.
[171] A. Charruyer, S. M. Bell, M. Kawano et al., "Decreased ceramide transport protein (CERT) function alters sphingomyelin production following UVB irradiation," Journal of Biological Chemistry, vol. 283, no. 24, pp. 16682-16692, 2008.

[172] T. Watanabe, H. Tsuge, T. Oh-Hara, M. Naito, and T. Tsuruo, "Comparative study on reversal efficacy of SDZ PSC 833, cyclosporin A and verapamil on multidrug resistance in vitro and in vivo," Acta Oncologica, vol. 34, no. 2, pp. 235-241, 1995.

[173] Y. Lavie, H. T. Cao, A. Volner et al., "Agents that reverse multidrug resistance, tamoxifen, verapamil, and cyclosporin A, block glycosphingolipid metabolism by inhibiting ceramide glycosylation in human cancer cells," Journal of Biological Chemistry, vol. 272, no. 3, pp. 1682-1687, 1997.

[174] A. Lucci, T. Y. Han, Y. Y. Liu, A. E. Giuliano, and M. C. Cabot, "Multidrug resistance modulators and doxorubicin synergize to elevate ceramide levels and elicit apoptosis in drug-resistant cancer cells," Cancer, vol. 86, no. 2, pp. 300311, 1999.

[175] M. C. Cabot, T. Y. Han, and A. E. Giuliano, "The multidrug resistance modulator SDZ PSC 833 is a potent activator of cellular ceramide formation," FEBS Letters, vol. 431, no. 2, pp. 185-188, 1998.

[176] N. Aouali, L. Eddabra, J. Macadré, and H. Morjani, "Immunosuppressors and reversion of multidrugresistance," Critical Reviews in Oncology/Hematology, vol. 56, no. 1, pp. 61-70, 2005.

[177] B. J. Maurer, L. Melton, C. Billups, M. C. Cabot, and C. P. Reynolds, "Synergistic cytotoxicity in solid tumor cell lines between $\mathrm{N}$-(4-hydroxyphenyl)retinamide and modulators of ceramide metabolism," Journal of the National Cancer Institute, vol. 92, no. 23, pp. 1897-1909, 2000.

[178] D. B. Jendiroba, J. Klostergaard, A. Keyhani, L. Pagliaro, and E. J. Freireich, "Effective cytotoxicity against human leukemias and chemotherapy-resistant leukemia cell lines by N-N-dimethylsphingosine," Leukemia Research, vol. 26, no. 3, pp. 301-310, 2002.

[179] S. Sarkar, M. Maceyka, N. C. Hait et al., "Sphingosine kinase 1 is required for migration, proliferation and survival of MCF-7 human breast cancer cells," FEBS Letters, vol. 579, no. 24, pp. 5313-5317, 2005.

[180] H. M. Sankala, N. C. Hait, S. W. Paugh et al., "Involvement of sphingosine kinase 2 in p53-independent induction of $\mathrm{p} 21$ by the chemotherapeutic drug doxorubicin," Cancer Research, vol. 67, no. 21, pp. 10466-10474, 2007.

[181] T. Shirahama, E. A. Sweeney, C. Sakakura et al., "In vitro and in vivo induction of apoptosis by sphingosine and $\mathrm{N}, \mathrm{N}$-dimethylsphingosine in human epidermoid carcinoma KB-3-1 and its multidrug-resistant cells," Clinical Cancer Research, vol. 3, no. 2, pp. 257-264, 1997.

[182] Z. Mao, W. Sun, R. Xu et al., "Alkaline ceramidase 2 (ACER2) and its product dihydrosphingosine mediate the cytotoxicity of N-(4-Hydroxyphenyl)retinamide in tumor cells," Journal of Biological Chemistry, vol. 285, no. 38, pp. 29078-29090, 2010.

[183] C. Ji, B. Yang, Y.-L. Yang et al., "Exogenous cell-permeable C6 ceramide sensitizes multiple cancer cell lines to Doxorubicininduced apoptosis by promoting AMPK activation and mTORC1 inhibition," Oncogene. In press.

[184] A. P. Bruno, G. Laurent, D. Averbeck et al., "Lack of ceramide generation in TF-1 human myeloid leukemic cells resistant to ionizing radiation," Cell Death and Differentiation, vol. 5, no. 2, pp. 172-182, 1998. 
[185] J. M. Michael, M. F. Lavin, and D. J. Watters, "Resistance to radiation-induced apoptosis in Burkitt's lymphoma cells is associated with defective ceramide signaling," Cancer Research, vol. 57, no. 16, pp. 3600-3605, 1997.

[186] C. P. Thomas, A. Buronfosse, V. Combaret, S. Pedron, B. Fertil, and J. Portoukalian, "Gangliosides protect human melanoma cells from ionizing radiation-induced clonogenic cell death," Glycoconjugate Journal, vol. 13, no. 3, pp. 377384, 1996

[187] S. Hara, S. Nakashima, T. Kiyono et al., "p53-independent ceramide formation in human glioma cells during $\gamma$ radiation-induced apoptosis," Cell Death and Differentiation, vol. 11, no. 8, pp. 853-861, 2004.

[188] S. Hara, S. Nakashima, T. Kiyono et al., "Ceramide triggers caspase activation during gamma-radiation-induced apoptosis of human glioma cells lacking functional p53," Oncology Reports, vol. 12, no. 1, pp. 119-123, 2004.

[189] C. L. Sawyers, A. Hochhaus, E. Feldman et al., "Imatinib induces hematologic and cytogenetic responses in patients with chronic myelogenous leukemia in myeloid blast crisis: results of a phase II study," Blood, vol. 99, no. 10, pp. 35303539, 2002.

[190] Y. Baran, A. Salas, C. E. Senkal et al., "Alterations of ceramide/sphingosine 1-phosphate rheostat involved in the regulation of resistance to imatinib-induced apoptosis in K562 human chronic myeloid leukemia cells," Journal of Biological Chemistry, vol. 282, no. 15, pp. 10922-10934, 2007.

[191] S. M. Wilhelm, C. Carter, L. Tang et al., "BAY 43-9006 exhibits broad spectrum oral antitumor activity and targets the RAF/MEK/ERK pathway and receptor tyrosine kinases involved in tumor progression and angiogenesis," Cancer Research, vol. 64, no. 19, pp. 7099-7109, 2004.

[192] V. Beljanski, C. Knaak, Y. Zhuang, and C. D. Smith, "Combined anticancer effects of sphingosine kinase inhibitors and sorafenib," Investigational New Drugs. In press.

[193] J. S. Norris, A. Bielawska, T. Day et al., "Combined therapeutic use of AdGFPFasL and small molecule inhibitors of ceramide metabolism in prostate and head and neck cancers: a status report," Cancer Gene Therapy, vol. 13, no. 12, pp. 1045-1051, 2006.

[194] R. C. Kane, A. T. Farrell, H. Saber et al., "Sorafenib for the treatment of advanced renal cell carcinoma," Clinical Cancer Research, vol. 12, no. 24, pp. 7271-7278, 2006.

[195] M. A. Tran, C. D. Smith, M. Kester, and G. P. Robertson, "Combining nanoliposomal ceramide with sorafenib synergistically inhibits melanoma and breast cancer cell survival to decrease tumor development," Clinical Cancer Research, vol. 14, no. 11, pp. 3571-3581, 2008. 

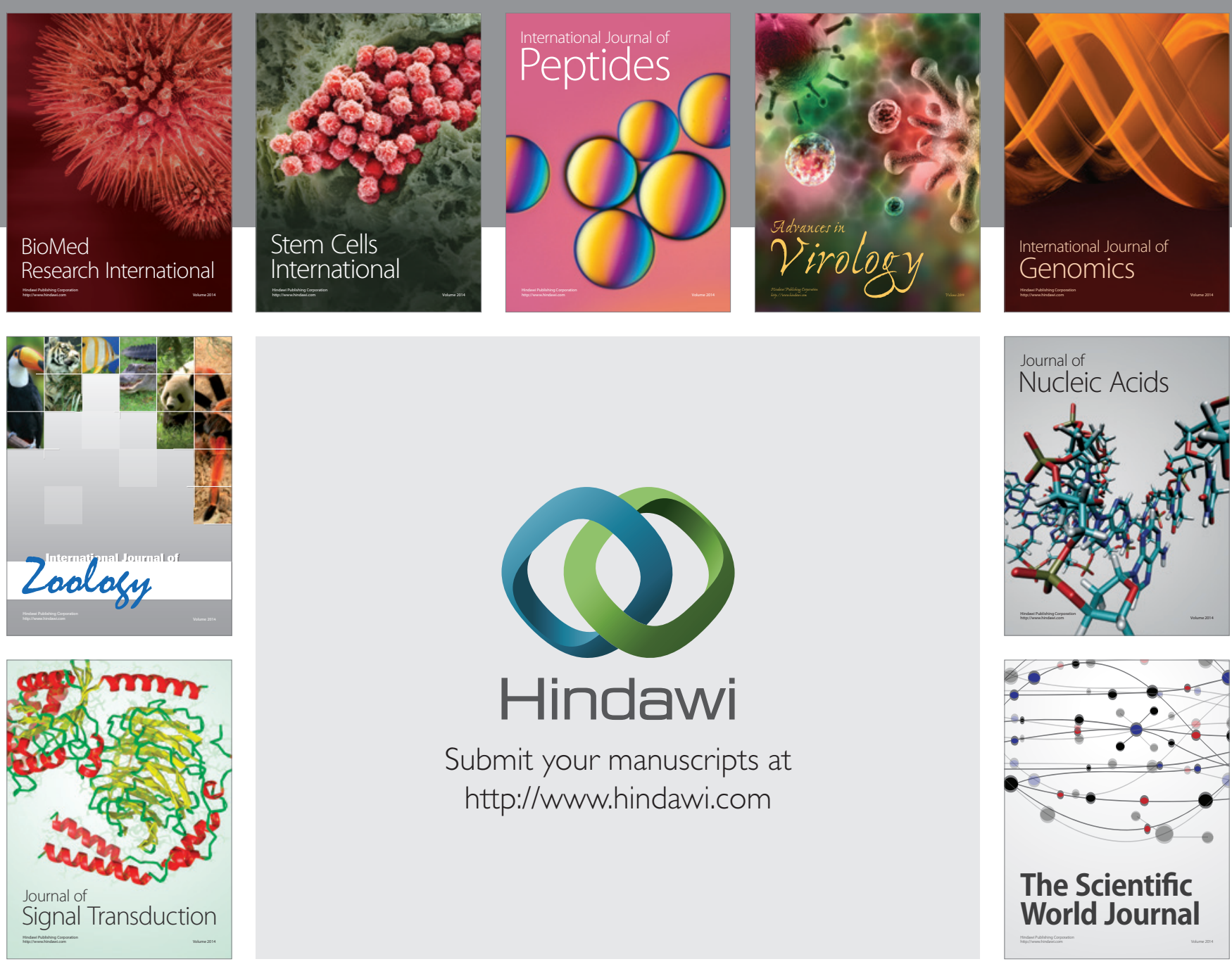

Submit your manuscripts at

http://www.hindawi.com
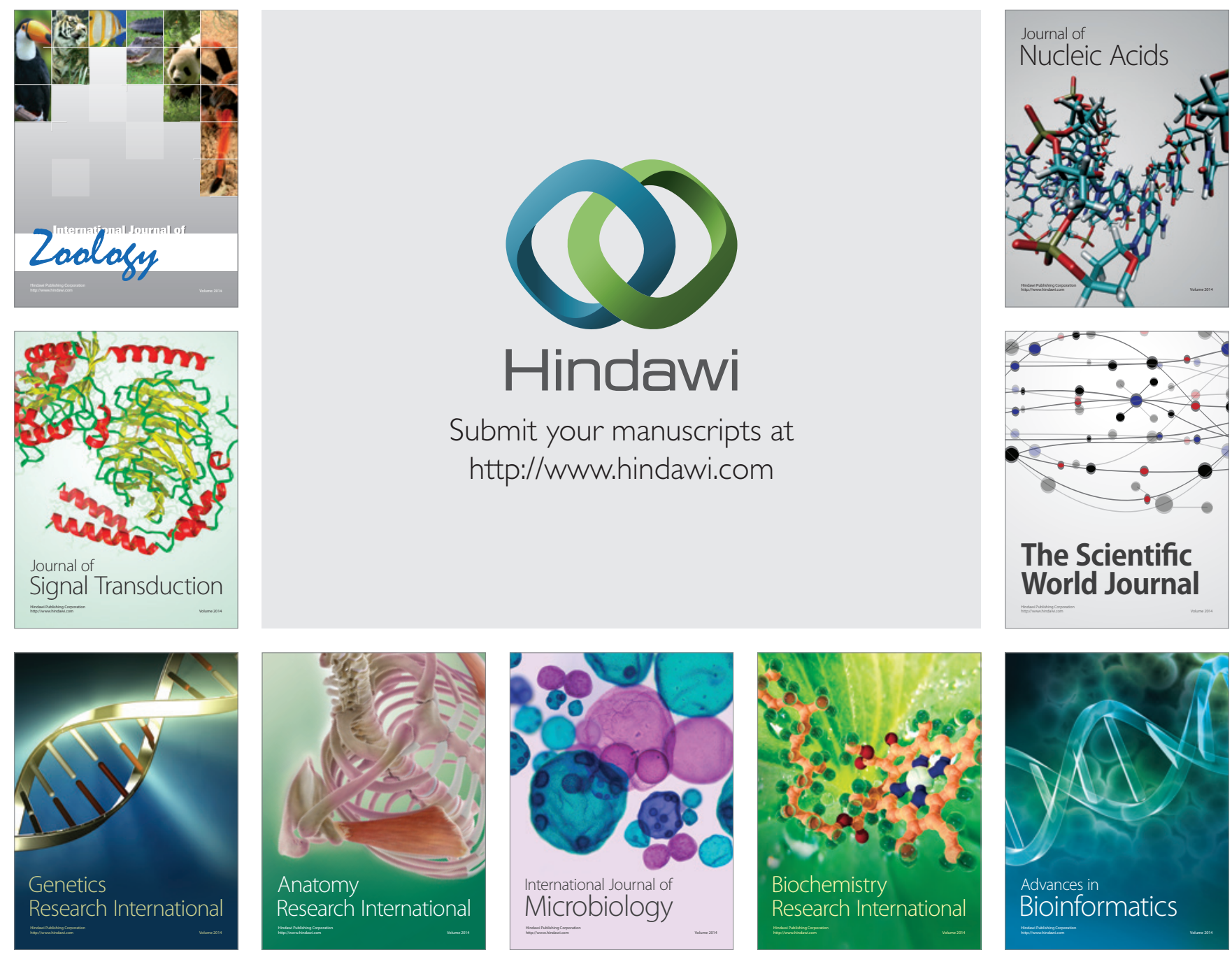

The Scientific World Journal
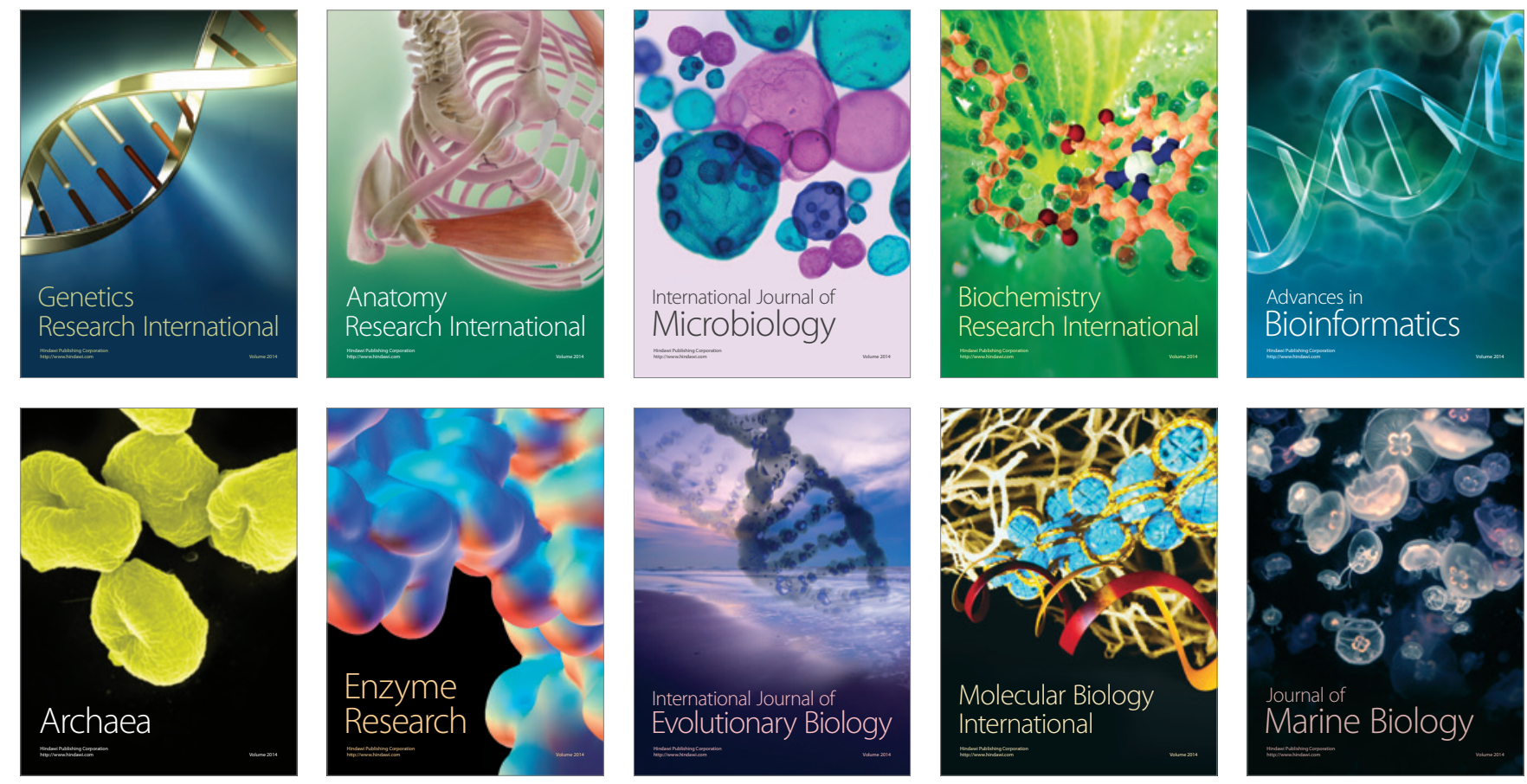